\title{
Is It Good to Cooperate? \\ Testing the Theory of Morality-as-Cooperation in 60 Societies
}

\author{
by Oliver Scott Curry, Daniel Austin Mullins, and Harvey Whitehouse
}

Online enhancements: supplemental appendix

\begin{abstract}
What is morality? And to what extent does it vary around the world? The theory of "morality-as-cooperation" argues that morality consists of a collection of biological and cultural solutions to the problems of cooperation recurrent in human social life. Morality-as-cooperation draws on the theory of non-zero-sum games to identify distinct problems of cooperation and their solutions, and it predicts that specific forms of cooperative behavior - including helping kin, helping your group, reciprocating, being brave, deferring to superiors, dividing disputed resources, and respecting prior possession - will be considered morally good wherever they arise, in all cultures. To test these predictions, we investigate the moral valence of these seven cooperative behaviors in the ethnographic records of 60 societies. We find that the moral valence of these behaviors is uniformly positive, and the majority of these cooperative morals are observed in the majority of cultures, with equal frequency across all regions of the world. We conclude that these seven cooperative behaviors are plausible candidates for universal moral rules, and that morality-as-cooperation could provide the unified theory of morality that anthropology has hitherto lacked.
\end{abstract}

Anthropology has struggled to provide an adequate account of morality. In 1962, the philosopher Abraham Edel (1962) complained that "anthropology has not furnished a systematic concept [of morality]" (67), and has avoided "the problem of morality, what it is, what identifying marks are to be sought for it, and how to go about mapping it" (56). Four decades later, little had changed. The anthropologist James Laidlaw (2002) lamented:

There is no anthropology of ethics . . . there is no sustained field of enquiry and debate. There is no connected history we can tell ourselves about the study of morality in anthropology, as we do for a range of topics such as kinship, the economy, the state, or the body. (311; see also, Laidlaw 2013)

Fortunately, the situation is now beginning to change. In recent years, the study of morality has become the focus of a thriving interdisciplinary endeavor, encompassing research not only in anthropology, but also in evolutionary theory, genetics, biology, animal behavior, psychology, neuroscience, and economics (Haidt 2007; Shackelford and Hansen 2016; SinnottArmstrong 2007). A common view in this body of work is that the function of morality is to promote cooperation (Curry 2016; Greene 2015:40; Haidt and Kesebir 2010:800; Rai and Fiske 2011:59; Sterelny and Fraser 2016:981; Tomasello and Vaish

Oliver Scott Curry is Senior Researcher, Daniel Austin Mullins is Postdoctoral Researcher, and Harvey Whitehouse is Chair of Social Anthropology at the Institute of Cognitive and Evolutionary Anthropology, University of Oxford, 64 Banbury Road, Oxford OX2 6PN, United Kingdom (oliver.curry@anthro.ox.ac.uk). This paper was submitted 13 V 16, accepted 22 XII 17, and electronically published 8 II 19.
2013:231). This cooperative account has the potential to provide anthropology with the unified theory of morality it has hitherto lacked. However, previous cooperative accounts have been limited in two main ways.

First, previous accounts have focused on a relatively narrow set of cooperative behaviors (typically kin altruism and reciprocal altruism) and omitted others (e.g., coordination and conflict resolution), and have thus attempted to explain morality from an unnecessarily restricted base. They have not used the mathematical analysis of cooperation, offered by the theory of non-zero-sum games, to provide a more systematic taxonomy of cooperation, and to thereby furnish a broader, more general theory of morality.

Second, previous empirical work has not established whether the cooperative account of morality applies cross-culturally, or whether there are cultures that provide counterexamples to the theory. In the absence of any agreed-upon theory of morality, previous work on cross-cultural moral variation has been patchy and inconsistent; different researchers have used different measures in different places, making the results impossible to combine or compare. In the absence of definitive empirical evidence, opinions have varied wildly, with some claiming that some morals are universal (Brown 1991), and others claiming that there are no such universals (Prinz 2007).

The present paper attempts to overcome these two limitations. First, we use non-zero-sum game theory to provide the cooperative approach to morality with a rigorous, systematic foundation. We show how this approach-which we call "morality-as-cooperation"-generates a rich, principled explanatory framework that incorporates more types of cooperation, 
and thus explains more types of morality, than previous approaches. Here we focus on seven well-established types of cooperation: (1) the allocation of resources to kin (Hamilton 1963); (2) coordination to mutual advantage (Lewis 1969); (3) social exchange (Trivers 1971); and conflict resolution through contests featuring displays of (4) hawkish and (5) dovish traits (Maynard Smith and Price 1973), (6) division (Skyrms 1996), and (7) possession (Gintis 2007). And we show how each type of cooperation explains a corresponding type of morality: (1) family values, (2) group loyalty, (3) reciprocity, (4) bravery, (5) respect, (6) fairness, and (7) property rights.

Second, to resolve uncertainty about the cross-cultural applicability of morality-as-cooperation, we test the theory's central prediction that each of these specific forms of cooperative behavior (helping kin, helping your group, reciprocating, being brave, deferring to superiors, dividing disputed resources, and respecting prior possession) will be considered morally good wherever they arise, in all cultures. We do this by investigating the moral valence of these cooperative behaviors in the ethnographic records of 60 societies, and examining their crosscultural frequency and distribution.

\section{Morality-as-Cooperation: An Overview}

The theory of morality-as-cooperation argues that morality consists of a collection of biological and cultural solutions to the problems of cooperation recurrent in human social life (Curry 2016). Below we review the general argument, before proceeding to look at specific types of cooperation and the corresponding types of morality that they explain.

Life begins when molecules start making copies of themselves. These "replicators" are "selfish" in the technical sense that they promote their own replication (Dawkins 2006 [1976]). They can promote their replication at the expense of other replicators. These competitive interactions have a winner and a loser; one's gain is another's loss; they are zero-sum games (Maynard Smith 1982; Von Neumann and Morgenstern 1944). But replicators can also replicate in concert with other replicators (Dawkins 1998). These cooperative interactions can have two winners; they are win-win situations; they are non-zero-sum games. Natural selection for genes that employ such cooperative strategies has driven several "major transitions" in the evolution of life on Earth, including the formation of cells, chromosomes, and multicellular organisms (Maynard Smith and Szathmáry 1995). Natural selection has also favored genes for cooperation between individuals, in a wide variety of species (Dugatkin 1997), including humans. Humans descend from a long line of social primates; they have spent 50 million years living in social groups (Shultz, Opie, and Atkinson 2011), and 2 million years making a living as intensely collaborative hunter-gatherers (Tooby and DeVore 1987). Evolution has equipped humans with a range of biological-including psychological-adaptations for cooperation. These adaptations can be seen as natural selection's attempts to solve the problems of cooperation. More recently, improvisational intelligence and cultural transmission (Boyd,
Richerson, and Henrich 2011; Pinker 2010) have made it possible for humans to attempt to improve upon natural selection's solutions by inventing evolutionarily novel solutions - "tools and rules"- for further bolstering cooperation (Binmore 1994a, 1994b; Hammerstein 2003; Nagel 1991; Popper 1945). Together, these biological and cultural mechanisms provide the motivation for social, cooperative, and altruistic behavior-leading individuals to value and pursue specific mutually beneficial outcomes. They also provide the criteria by which individuals recognize, evaluate, and police the cooperative behavior of others. And, according to the theory of morality-as-cooperation, it is precisely these multiple solutions to problems of cooperationthis collection of instincts, intuitions, inventions, and institutions - that constitute human morality (Curry 2005, 2016).

Which problems of cooperation do humans face? And how are they solved? Evolutionary biology and game theory tell us that there is not just one problem of cooperation but many, with many different solutions (Lehmann and Keller 2006; Nunn and Lewis 2001; Robinson and Goforth 2005; Sachs et al. 2004). Hence morality-as-cooperation predicts that there will be many different types of morality. Below we review seven well-established types of cooperation: (1) the allocation of resources to kin; (2) coordination to mutual advantage; (3) social exchange; and conflict resolution through contests featuring (4) hawkish displays of dominance and (5) dovish displays of submission; (6) division of disputed resources; and (7) recognition of possession.

\section{Allocation of Resources to Kin (Family Values)}

Genes that benefit replicas of themselves in other individualsthat is, genetic relatives - will be favored by natural selection if the cost of helping is outweighed by the benefit to the recipient gene(s) (Dawkins 1979; Hamilton 1964). So, evolutionary theory leads us to expect that under some conditions organisms will possess adaptations for detecting and delivering benefits (or avoiding doing harm) to kin. This theory of kin selection explains many instances of altruism, in many species (Gardner and West 2014), including humans (Kurland and Gaulin 2005; Lieberman, Tooby, and Cosmides 2007). Morality-as-cooperation leads us to expect that this type of cooperative behaviorcaring for offspring, helping family members, and avoiding inbreeding — will be regarded as morally good.

\section{Coordination to Mutual Advantage (Group Loyalty)}

Game theory models situations in which individuals are uncertain about how to behave to bring about a mutual benefit as coordination problems (Lewis 1969). Humans and other animals use a variety of strategies - such as focal points, traditions, leadership, signaling, badges of membership, and "theory of mind"to solve these problems (Alvard 2001; Boos et al. 2011; McElreath, Boyd, and Richerson 2003) and form stable coalitions and alliances (Balliet, Wu, and De Dreu 2014; Bissonnette et al. 2015; Harcourt and de Waal 1992). Morality-as-cooperation 
leads us to expect that this type of cooperative behavior - forming friendships, participating in collaborative endeavors, favoring your own group, and adopting local conventions - will be regarded as morally good.

\section{Social Exchange (Reciprocity)}

In game theory, social dilemmas - prisoners' dilemmas, public goods games, tragedies of the commons - arise when the fruits of cooperation are vulnerable to exploitation by "free riders," who accept the benefit of cooperation without paying the cost (Ostrom and Walker 2002). This problem can be overcome by a strategy of "conditional cooperation" or "reciprocal altruism," such as tit-for-tat (Axelrod 1984; Trivers 1971). Evidence for various aspects of conditional cooperation have been found in numerous animal species (Carter 2014), including humans (Cosmides and Tooby 2005; Henrich et al. 2005; Jaeggi and Gurven 2013). Morality-as-cooperation leads us to expect that this type of cooperative behavior - trusting others, reciprocating favors, seeking revenge, expressing gratitude, and making amends - will be regarded as morally good.

\section{Contests between Hawks (Bravery) and Doves (Respect)}

Conflict over resources - food, territory, and mates (Huntingdon and Turner 1987) — presents organisms with an opportunity to cooperate by competing in less mutually destructive ways (Maynard Smith and Price 1973). There are three ways of achieving this: contests (featuring the display of hawkish and dovish traits), division, and possession.

Game theory has shown that conflicts can be settled through "contests," in which individuals display reliable indicators of their "fighting ability," and defer to the stronger party (Gintis, Smith, and Bowles 2001; Maynard Smith and Price 1973). Such contests are widespread in nature (Hardy and Briffa 2013; Riechert 1998), and often form the basis of dominance hierarchies where resources are allocated by "rank" (Preuschoft and van Schaik 2000). Humans have a similar repertoire of statusrelated behaviors (Fiddick et al. 2013; Mazur 2005; Sell, Tooby, and Cosmides 2009), and culturally elaborated hierarchies (Boone 1992; Rubin 2000). Morality-as-cooperation leads us to expect that these types of cooperative behavior-hawkish displays of dominance (the "heroic virtues" of bravery, fortitude, skill, and wit) and dovish displays of submission (the "monkish virtues" of humility, deference, obedience, and respect)—will be regarded as morally good (Curry 2007).

\section{Division (Fairness)}

When the contested resource is divisible, game theory models the situation as a "bargaining problem" (Nash 1950). Here, one solution is to divide the resource in proportion to the relative (bargaining) power of the protagonists (Skyrms 1996). In the case of equally powerful individuals, this results in equal shares (Maynard Smith 1982). Evidence for a "sense of fairness" comes from nonhuman primates' adverse reactions to unequal treat- ment in economic games (Brosnan 2013). With regard to humans, rules such as "I cut, you choose," "meet in the middle," "split the difference," and "take turns" are ancient and widespread means of resolving disputes (Brams and Taylor 1996). And "equal shares" is a spontaneous and cross-culturally prevalent decision rule in economic games (Henrich et al. 2005) and similar situations (Messick 1993). Morality-as-cooperation leads us to expect that this type of cooperative behavior- dividing disputed resources, reaching a compromise, being fairwill be regarded as morally good.

\section{Possession (Property Rights)}

Finally, game theory shows that conflicts over resources can be resolved by recognition of prior possession (Gintis 2007; Hare, Reeve, and Blossey 2016; Maynard Smith 1982). The recognition of prior possession is widespread in nature (Strassmann and Queller 2014). Humans also defer to prior possession in vignette studies (DeScioli and Karpoff 2015; Friedman and Neary 2008), experimental games (the "endowment effect"; Kahneman and Tversky 1979), the law (Rose 1985), and international relations (Johnson and Toft 2014). Private property, in some form or other, appears to be a cross-cultural universal (Herskovits 1952). Morality-as-cooperation leads us to expect that this type of cooperative behavior-deferring to prior possession - will be regarded as morally good.

\section{Summary}

Thus morality-as-cooperation uses the theory of non-zero-sum games to identify distinct problems of cooperation and their solutions, and thereby generates a deductive framework in which to make sense of morality. The present incarnation of the theory incorporates seven well-established types of cooperation-helping family, helping group, exchange, resolving conflicts through hawkish and dovish displays, dividing disputed resources, and respecting prior possession - and uses this framework to explain seven types of morality - obligations to family, group loyalty, reciprocity, bravery, respect, fairness, and property rights.

Morality-as-cooperation's theory-driven approach provides broader and more detailed coverage of the moral domain than previous approaches that are not guided by these theories of cooperation. For example, whereas morality-as-cooperation proposes seven moral domains, moral foundations theory (MFT) proposes only five: care, fairness, ingroup, authority, and purity (Graham et al. 2011; Haidt and Graham 2007). MFT's scheme omits several well-established types of cooperation: there is no foundation dedicated to kin altruism, or to reciprocal altruism, or to hawkish displays of dominance such as bravery, or to property rights. ${ }^{1}$ And MFT includes two

1. MFT conflates reciprocity (a solution to iterated prisoners' dilemmas) with fairness (a solution to bargaining problems). What's more, there are no items pertaining to reciprocity in the questionnaire designed to measure the moral foundations (Graham et al. 2011). 
foundations - care and purity - that are not related to any specific type of cooperation (and which morality-as-cooperation predicts will not constitute distinct moral domains). "Care"like "altruism" - is a generic term that does not distinguish between forms of prosocial behavior with different ultimate and proximate roots. And "purity" - avoiding "people with diseases, parasites [and] waste products" (Haidt and Joseph 2004:59) has no explicated connection to cooperation at all. ${ }^{2}$ Moreover, whereas morality-as-cooperation can look to advances in game theory to identify new forms of cooperation, and thereby generate new predictions and explanations of moral phenomena, MFT's avowedly ad hoc approach (Haidt and Joseph 2011) is unable to make any such predictions.

Thus, by using the logic of game theory, morality-ascooperation is able to state the cooperative thesis with greater precision, and explain and predict a broader array of moral phenomena, than previous cooperative accounts of morality. And it is to those predictions that we now turn.

\section{Is Cooperation Considered Morally Good in All Cultures?}

As we have seen, the theory of morality-as-cooperation predicts that specific forms of cooperative behavior - helping kin, helping one's group, reciprocating costs and benefits, displaying hawkish and dovish traits, dividing disputed resources, and respecting prior possession - will be regarded as morally good. Conversely, the theory predicts that the corresponding forms of uncooperative behavior - neglecting kin, betraying one's group, free-riding, cowardice, disrespect, unfairness, and theft - will be regarded as morally bad. Moreover, morality-as-cooperation predicts that, to the extent these problems of cooperation are universal features of human social life, these cooperative behaviors will be considered morally good in all moral systems, in all cultures - there will be no cultures in which any of these types of cooperative behavior are considered morally bad. ${ }^{3}$ These seven moral values will be universal.

2. Indeed, "purity" is described as an "odd corner" of morality precisely because it is not "concerned with how we treat other people" (Haidt and Joseph 2004:60).

3. Moral dilemmas arise when one form of cooperative behavior is incompatible - and comes into conflict — with another, and some decision or trade-off must be made between them. Thus the theory of morality-ascooperation predicts also that the only time a form of cooperative behavior will be considered morally bad will be when it is pursued at the expense of some other larger form of cooperation - as in the case of thieves loyally cooperating to rob a bank. Conversely, the only time a form of uncooperative behavior will be considered morally good will be when it facilitates some larger cooperative outcome - as in the case of a whistle-blowing employee disobeying her boss to report a crime. In other words, cooperative behavior will only ever be considered morally bad relative to some other, greater opportunity for cooperation. In all cases the underlying moral criterion remains: "Does this behavior promote cooperation?"
Previous empirical work on morality in diverse culturescomparative anthropology and questionnaire-based researchprovides some support for these predictions (see table S1, available online).

\section{Helping Kin}

A survey of the ethnographic records of "Pleistoceneappropriate foragers" found that kin altruism was "socially favored" in 10 of 10 societies (Boehm 2008). In addition, a survey of family values involving student samples from 30 countries (Byrne and van de Vijver 2014; Georgas et al. 2006; Graham et al. 2011) and responses to items in the World Values Survey, conducted in over 65 societies (Inglehart and Baker 2000), indicate that "helping kin" is widely considered to be morally good.

\section{Helping Your Group}

A review of the Standard Cross-Cultural Sample reveals that loyalty to the local community is "moderate" to "especially high" in 77 of 83 cultures for which there is data, loyalty to the wider society is "moderate" to "especially high" in 60 of 84 cultures (Murdock and White 2006, V778-V779; Ross 1983), and loyalty within ethnic groups is "middle" to "high" in 45 of 86 cultures (Lang 1998; Murdock and White 2006, V1771). ${ }^{4}$ In addition, responses to the Ingroup items in the Moral Foundations Questionnaire from "Eastern" and "Western" internet samples (Graham et al. 2011), and responses to items from the Schwartz Basic Values Survey, from student samples in 20 countries (Schwartz 1992), indicate that "helping your group" is widely considered to be morally good.

\section{Positive and Negative Reciprocity}

There is evidence that "cheating" is considered morally deviant in 5 of 10 foraging societies (Boehm 2008). Taking revenge is prescribed in 48 of 80 cultures for which there are data (Murdock and White 2006, V704), and kin group vengeance is considered legitimate in 90 (and a moral imperative in 38) of 168 societies for which there are data (Ericksen and Horton 1992; Murdock and White 2006, V2008). In addition, endorsement of the norms of positive and negative reciprocity in student samples (Eisenberger et al. 2004), in Britain and Italy (Perugini et al. 2003), and responses to some items in the Values in Action Inventory of Strengths in 54 countries (Park, Peterson, and Seligman 2006; Peterson and Seligman 2004) and Schwartz's Values Scale (Schwartz 1992) indicate that "reciprocating costs and benefits" is widely considered to be morally good.

4. Variables shown for Murdock and White (2006) refer to the "Standard Cross-Cultural Sample: Codebook," http://eclectic.ss.uci.edu/ drwhite /courses/SCCCodes.htm. 


\section{Hawkish Traits}

Toughness (encompassing fortitude, aggression, and competitiveness) is among the traits widely inculcated in children in a majority of cultures (Barry et al. 1976; Murdock and White 2006, V294-V305, V322-V325). In addition, a series of investigations into the concept of honor among students in the United States and Turkey (Cross et al. 2014) indicates that various hawkish traits are considered to be morally good.

\section{Dovish Traits}

Obedience is also among the traits widely inculcated in children in a majority of cultures (Barry et al. 1976; Murdock and White 2006, V294-V305, V322-V325). In addition, responses to the Authority items in the Moral Foundations Questionnaire (Graham et al. 2011) and to items from the Schwartz Basic Values Survey (Schwartz 1992) indicate that "respecting superiors" is widely considered to be morally good.

\section{Dividing Disputed Resources}

Responses to items in the Merit Principle Scale in student samples (Davey et al. 1999) indicate that "dividing disputed resources" is considered to be morally good.

\section{Possession}

Recognition of private property is present in 70 of 84 cultures for which there is data (Murdock and White 2006, V704; Whyte 2005). In addition, punitive attitudes to "theft" in six cultures (Newman 1976) and responses to items in the World Values Survey (reported in Weeden and Kurzban 2013) indicate that "respecting property" is widely considered to be morally good.

\section{Unanswered Questions}

However, these heterogenous studies were not designed to, and indeed do not, test fully morality-as-cooperation's specific predictions. Comparative anthropology has not systematically assessed the moral valence of all seven forms of cooperative behavior: moral values relating to hawkish and dovish traits in the adult population, and dividing disputed resources, are conspicuously absent from the literature. And no previous questionnaire research has evaluated all seven types of cooperative behavior posited by the theory: existing scales typically measure something other than moral valence (e.g., they ask whether a person or a society possesses a particular trait, rather than whether the trait is moral); and the disparate samples are typically university students, or people in Western, educated, industrialized, rich, democratic (WEIRD) societies (Henrich, Heine, and Norenzayan 2010), or people with access to the internet, which limits their external validity and generalizability to "humanity" at large.
Thus, as Machery and Mallon (2010) put it:

We do not know whether moral norms are present in every culture . . because . . researchers have simply not shown that, in numerous cultures, there are norms that fit some rich characterization of moral norms. (35)

And this uncertainty is reflected in the diversity of opinions about the universality or otherwise of moral values - opinions which range from one extreme to the other.

At one end of the spectrum, it has been argued that morality is universal. A classic statement of this position was provided by the philosopher David Hume (1751), who argued that moral judgments depend on an "internal sense or feeling, which nature has made universal in the whole species" (6-7), and that as a result certain qualities - such as "truth, justice, courage, temperance, constancy, dignity of mind . . . friendship, sympathy, mutual attachment, and fidelity" (238-239) - are "the most universal, established principles of morals" (238), "esteemed universally, since the foundation of the world" (241), "in all nations and all ages" (239). More recently, the anthropologist Donald Brown (1991) has claimed that moral notions of reciprocity, generosity, empathy, etiquette, hospitality, sexual modesty, and property are universals, present in every society. ${ }^{5}$

At the other end of the spectrum, it has been argued that morality is not universal, but varies dramatically. The philosopher John Locke (1690), for example, argued:

He that will carefully peruse the history of mankind, and look abroad into the several tribes of men . . . will be able to satisfy himself, that there is scarce that principle of morality to be named, or rule of virtue to be thought on . . . which is not, somewhere or other, slighted and condemned by the general fashion of whole societies of men. (19)

More recently, the Executive Board of the American Anthropological Association (1947) has argued:

Ideas of right and wrong, good and evil, are found in all societies, though they differ in their expression among different peoples. What is held to be a human right in one society may be regarded as anti-social by another people, or by the same people in a different period of their history. (542)

And the philosopher Jesse Prinz (2007) concluded that "it is difficult to find examples of moral universals. The rules by which people abide vary across cultural boundaries" (380). "If there are substantive universal moral rules or moral domains, they have yet to be identified" (387). "Moral rules show amazing variation across cultures" (403).

Thus it remains unclear whether morality-as-cooperation's predictions hold across all cultural groups. And so, to provide a robust test of these predictions, in a way that overcomes the limitations of previous research and resolves lingering uncertainty over cross-cultural variation in moral values, we sur-

5. Note that Human Universals (Brown 1991) does not provide any data, and no such data exist. And so these claims should be viewed as hypotheses awaiting evidence, rather than evidence in themselves. 
veyed the moral valence of the seven cooperative behaviors in a single, homogenous, coherent source of high-quality ethnographic data, collected from a sample of 60 societies specifically chosen to provide as representative a sample of humanity as possible - a sample that provides the best chance of identifying potential counterexamples to the theory.

In addition to reporting the moral valence of these cooperative behaviors, we also report their cross-societal frequency and distribution. After all, it is possible that even if morality-ascooperation's predictions regarding the moral valence of cooperative behaviors are supported, these behaviors and their corresponding moral values may still turn out to be rare, present in relatively few societies, or in only some regions but not others.

\section{Methods}

To test the prediction that the seven cooperative behaviors would be regarded as morally good, and to establish the cross-cultural prevalence of the moral values that result, we undertook a content analysis of the ethnographic record of 60 societies, using the holocultural method (Ember and Ember 2009; Otterbein 1969).

We began by assembling ethnographic descriptions of morality from the digital version of the Human Relations Area Files (eHRAF) - an archive of thousands of original, full-text ethnographies from hundreds of societies of varying complexity, from simple hunter-gatherer bands to kingdoms and modern states. For this study we focused on the 60 societies that constitute the Probability Sample Files, a stratified random sample of wellattested human societies, drawn from the six regions of the globe (Sub-Saharan Africa, Circum-Mediterranean, East Eurasia, Insular Pacific, North America, South America; Lagacé 1979). This sample of societies was constructed to minimize the effects of "Galton's problem"- the nonindependence between crosscultural data points (Atkinson and Whitehouse 2011; Mace et al. 1994; Naroll 1967). The ethnographic coverage of these 60 societies conforms to rigorous ethnographic criteria, including the requirements that at least 1,200 pages of reliable, well-rounded cultural data are available for each society, and that one or more professionally trained ethnographers stayed in that society for more than a year and had a working knowledge of the native language(s) (HRAF 1967). For the specific geographic location of these 60 societies, see figure 1 .

Relevant ethnographic material was identified and collected from eHRAF in two phases. In the first phase, we extracted paragraph-level ethnographic materials indexed by professional anthropologists for the eHRAF as Ethics or Norms. ${ }^{6}$ The ex-

6. eHRAF describes the subject code Ethics (577) as follows: "Abstract ethical ideals (e.g., truth, righteousness, justice); ideals of individual virtue (e.g., honesty, loyalty, industry, courage, temperance, tolerance, filial piety); notions of right and wrong; conception of conscience and character; incidence and causes of, and attitudes toward breaches of ethics (e.g., lying, cowardice, flouting of kinship obligations); conflicts between ideal values and practical considerations; gender-typed attitudes and values; etc." And eHRAF describes the subject code Norms (183) as: "Native and scientific traction of materials indexed as Ethics resulted in 2,519 paragraphs from 400 documents across the 60 societies sampled. The extraction of materials indexed as Norms resulted in 1,605 paragraphs from 263 discrete documents across 58 of the societies sampled. We then conducted a second phase of data collection to exhaust all relevant material in the ethnographic archive. In this phase, the entire archive was searched using a combination of relevant indexical headings (e.g., "Mutual Aid") and keyword combinations (Altheide 1987; Krippendorff 2012; for the full search syntax, see table S2, available online). This phase identified 1,737 paragraphs from 355 discrete documents across the 60 societies. When duplicate paragraphs were removed (i.e., 2,401 paragraphs identified in more than one phase), we were left with a total of 3,460 paragraphs, containing 606,556 words, from 603 unique sources, published over a period spanning 300 years. $^{7}$

We then operationalized the seven types of cooperative behavior under investigation and constructed a codebook that specified how to identify and code them in the ethnographic source material (shown in table 1). For kinship and mutualism, we looked for cases in which family or group were helped or given special treatment. Reciprocity included both positive and negative (revenge) forms. Because hawkish displays of prowess encompass several different behaviors - strength, bravery, generosity - we decided to focus on one particular example, bravery. For dovish displays, we focused on respect for, and allegiance to, elders and chiefs. For division, we looked specifically for instances in which dividing a resource resolved or forestalled a conflict (and not merely cases in which resources were "shared"). And finally, we looked for cases where objects or resources were controlled by their possessor.

Having identified instances of the cooperative behaviors of interest, the next task was to determine whether they were presented in a morally valenced way, and if so whether the valence was positive or negative. Thus the code book instructed coders to record whether the behavior was described as good, right, moral, ethical, or virtuous, or as an obligation, duty, or moral norm, and so on. It could also be indicated by morally valenced words. For example, the mere mention of "family loyalty" or "property rights" would suffice to indicate the presence of a positive moral valence.

The coding procedure involved making 24,220 (3,460 × 7) coding decisions - that is, deciding whether or not each of the 3,460 paragraphs indicated that any of the seven cooper-

definitions of custom (e.g., as ideal patterns, as ranges of variation within limits, as statistical inductions from observed behavior); positive and negative norms (e.g., folkways, taboos); verbalized and covert norms; investment of norms with affect and symbolic value (e.g., mores, idealization); discrepancies between ideals and behavior; configurations of norms (e.g., culture complexes, institutions); etc." Full descriptions of all eHRAF subjects can be found here: http://hraf.yale.edu/online-databases/ehraf-world-cultures /outline-of-cultural-materials/.

7. Year of publication: $n=603$, mean $=1961, \mathrm{SD}=30$, median $=$ 1967 , minimum $=1704$, maximum $=2009$. 


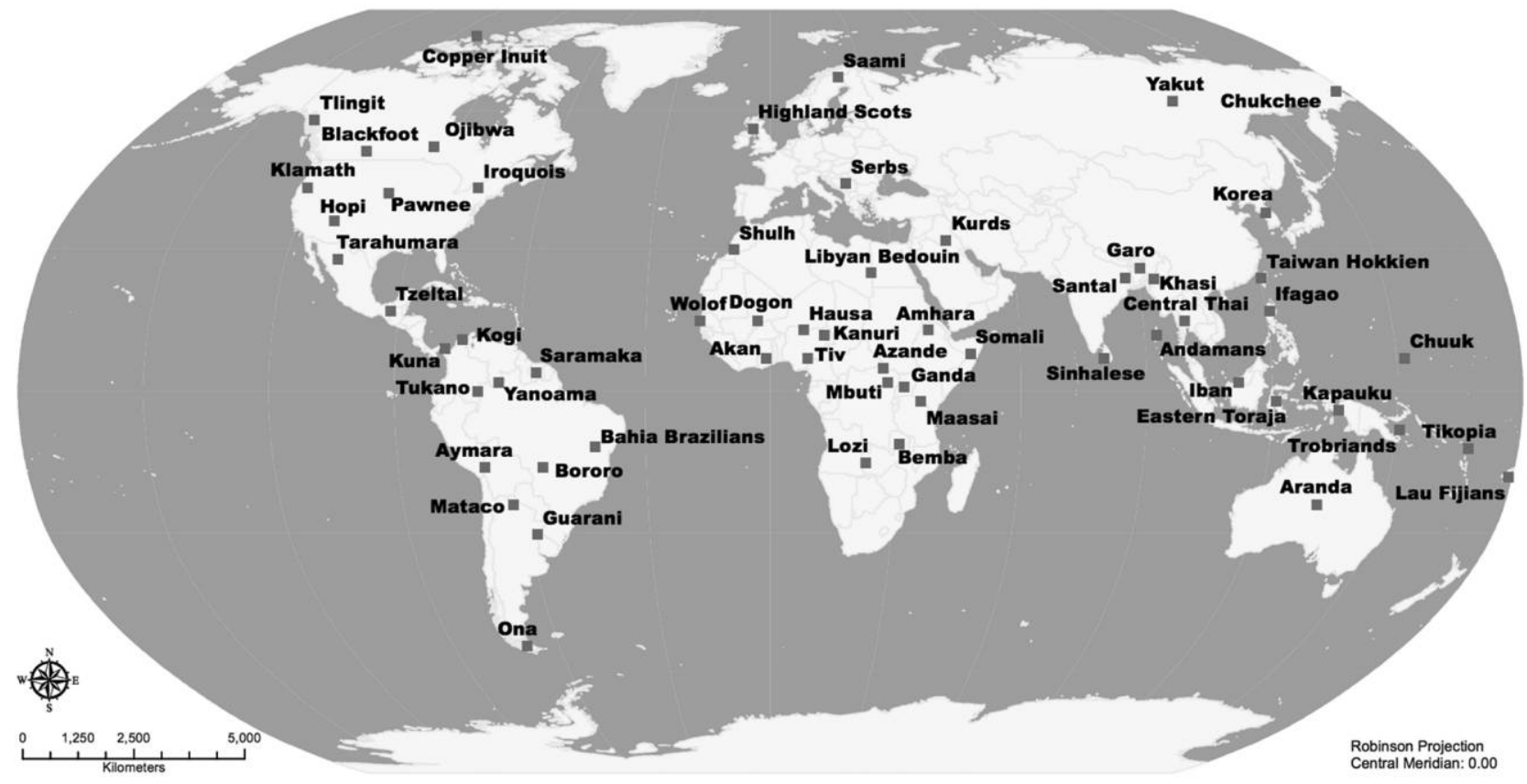

Figure 1. Locations of 60 Probability Sample Files Societies.

ative behaviors had a positive or negative moral valence. ${ }^{8}$ Raters 1 and 2 (authors O.S.C. and D.A.M.) independently coded the full set of 3,460 paragraphs and then conferred to resolve ambiguities and discrepancies. This resulted in a total of 1,426 paragraphs that contained material germane to one or more moral domain. A hypothesis-blind independent coder (rater 3) then coded each of these 1,426 paragraphs before discussing coding discrepancies with raters 1 and 2 . Of the $1,426 \times$ $7=9,982$ initial coding decisions compared between the two sets of codes, there were 8,704 decisions in agreement and 1,278 decisions on which the raters disagreed - thus there was "moderate" agreement between the two initial sets of ratings overall $(\kappa=.58, P<.005)$ (Cohen 1960, 1968; Landis and Koch 1977). By type of cooperation, the degree of agreement between the two sets of ratings were: "helping kin" $(\kappa=0.52$; "moderate"); "helping your group" ( $\kappa=0.47$; "moderate");

8. The instructions to coders were as follows: "Please read through the following paragraphs. Your task is to decide, for each paragraph, whether it contains evidence that any of seven behaviors explained in table 1 is considered morally good or bad. 'Moral goodness' may be indicated by comments to the effect that the particular behavior is good, right, moral, ethical, or virtuous, or that it is an obligation, duty, or moral norm, and so on. It may also be indicated by morally-valenced words. For example, the mere mention of 'family loyalty,' or 'property rights' would suffice. Moral goodness can also be indicated by evidence that not performing the particular behavior is bad, wrong, immoral or unethical, etc. Similarly, moral badness maybe indicated by comments to the effect that the particular behavior is bad, wrong, immoral, unethical, or sinful, or that it is taboo, shameful, prohibited, and so on. If there is evidence that the particular behavior is considered morally good, then type ' 1 ' in the adjacent box. If the behavior is considered morally wrong, then type ' -1 .' Please bear in mind that any given paragraph may contain evidence that several different behaviors are considered moral (or immoral)." "reciprocity" ( $\kappa=0.66$; "good"); "bravery" ( $\kappa=0.65 ;$ "good"); "respect for superiors" ( $\kappa=0.56$; "moderate"); "dividing disputed resources" ( $\kappa=0.14$; "poor"); "property" ( $\kappa=0.75$; "good"). ${ }^{9}$ Raters 1, 2, and 3 met to discuss and analyze discrepancies using the resolution method (Ember and Ember 2009). On closer inspection it was discovered that the poor level of agreement with regard to "dividing disputed resources" was the result of rater 3 including cases of generic "sharing." These and other rating discrepancies were reviewed and resolved until complete agreement was reached $(\kappa=1)$.

In the final analysis, of the 3,460 paragraphs reviewed, 761 contained information about the moral valence of one

9. All $P$-values <.001. Although there was some disagreement about whether particular paragraphs should be coded as positive or not, there was no disagreement about whether a paragraph should be coded as positive or negative. And so although the coding of any given paragraph could be challenged (and altered), any such alternation would be very unlikely to alter the sign of the data (from positive to negative), and as such would not make any substantive difference to the main result. Also, although "explicit moral indifference" to a cooperative behavior was not coded during the official review process, in response to a reviewer query we can confirm that: $(a)$ any such cases would have certainly caught our attention; and $(b)$ there were no such cases.

10. With respect to "dividing disputed resources," the raters agreed on the absence of evidence of fairness in 1,219 cases and the presence of fairness in 22 cases. However, raters 1 and 2 rated 37 cases as containing evidence of fairness when rater 3 rated them as absent, and rater 3 rated 148 cases as containing evidence of fairness when raters 1 and 2 rated them as absent. There was indeed ample praise for "sharing" (along with generosity, largesse, and condemnation of stinginess). However, like the term "altruism," it was difficult to determine whether such sharing was directed at kin, group members, friends, or people in general, and thus often impossible to code. 
Table 1. Morality-as-cooperation codebook

\begin{tabular}{|c|c|c|c|}
\hline & Namely & For example & Is \\
\hline 1. Family & Helping family members & $\begin{array}{l}\text { Being a loving mother } \\
\text { Being a protective father } \\
\text { Helping a brother } \\
\text { Caring for a frail relative } \\
\text { Passing on property to your offspring } \\
\text { Avenging the death of a relative } \\
\text { Siding with your family in a dispute } \\
\text { Giving preferential treatment to your family } \\
\text { Being responsible for what a member of your family does } \\
\text { ("corporate responsibility") }\end{array}$ & \\
\hline 2. Group & Helping group members & $\begin{array}{l}\text { Working together/in a team } \\
\text { Coordinating your behavior with others } \\
\text { Forming and maintaining friendships, alliances, and coalitions } \\
\text { Adopting local conventions } \\
\text { Joining in with group activities and events } \\
\text { Siding with your group in a dispute } \\
\text { Giving preferential treatment to (members of) your group } \\
\text { Promoting group harmony, unity, solidarity } \\
\text { Being responsible for what a member of your group does } \\
\text { ("corporate responsibility") } \\
\text { Going to war to defend your group }\end{array}$ & $\begin{array}{l}\text { Good } \\
\text { Right } \\
\text { Moral } \\
\text { Ethical } \\
\text { Virtuous } \\
\text { An obligation } \\
\text { A duty } \\
\text { A moral norm } \\
\text { Et cetera }\end{array}$ \\
\hline 3. Reciprocity & $\begin{array}{l}\text { Engaging in reciprocal } \\
\text { cooperation }\end{array}$ & $\begin{array}{l}\text { Trusting someone } \\
\text { Returning a favor } \\
\text { Paying a debt } \\
\text { Fulfilling a contract } \\
\text { Seeking compensation or revenge for an injury } \\
\text { Feeling guilt for failure to reciprocate } \\
\text { Making amends for cheating } \\
\text { Forgiving people when they apologize }\end{array}$ & $\begin{array}{l}\text { OR } \\
\text { Bad } \\
\text { Wrong } \\
\text { Immoral } \\
\text { Unethical } \\
\text { Evil }\end{array}$ \\
\hline 4. Bravery & Being brave & $\begin{array}{l}\text { Being strong, tough, able to withstand pain and discomfort } \\
\text { Being brave, courageous, heroic (especially in battle) } \\
\text { Putting yourself at risk to help others } \\
\text { Being ready, willing, and able to take on challenges }\end{array}$ & $\begin{array}{l}\text { A vice } \\
\text { A sin } \\
\text { Et cetera }\end{array}$ \\
\hline 5. Respect & Respecting your superiors & $\begin{array}{l}\text { Being deferential, respectful, loyal, or obedient to those } \\
\text { above you in a hierarchy } \\
\text { Using appropriate forms of address and etiquette } \\
\text { Showing respect to parents and older members of society } \\
\text { Being duly respectful of peers and rivals }\end{array}$ & \\
\hline 6. Fairness & $\begin{array}{l}\text { Sharing or dividing } \\
\text { a disputed resource }\end{array}$ & $\begin{array}{l}\text { Dividing a disputed resource, rather than fighting over it } \\
\text { Diving the spoils of a collective enterprise equally, impartially, } \\
\text { or according to effort/contribution (as opposed to showing favoritism) } \\
\text { Being willing to negotiate, compromise, come to an agreement } \\
\text { Meeting in the middle, for example when resolving territorial } \\
\text { border disputes }\end{array}$ & \\
\hline 7. Property & Respecting others' property & $\begin{array}{l}\text { Respecting others' property, possessions, and territory } \\
\text { Not thieving, stealing, robbing (from your group at least) } \\
\text { Not damaging others' property, or using without permission } \\
\text { Not trespassing } \\
\text { Respecting people's homes, personal space }\end{array}$ & \\
\hline
\end{tabular}

or more of the seven cooperative behaviors. This gave rise to 962 observations of moral valence in total.

\section{Results}

In 961 out of 962 observations (99.9\%), cooperative behavior had a positive moral valence. The results for each type of cooperative behavior are given in table 2 . The one exception to the rule - among the Chuuk, "to steal openly from others is ad- mirable in that it shows a person's dominance and demonstrates that he is not intimidated by the aggressive powers of others" (Caughey 1977) - appears to be a case in which one form of cooperation (respect for property) has been trumped by another (respect for a hawkish trait, although not explicitly bravery). ${ }^{11}$

11. There were 18 other examples of these seven moral values coming into conflict: nine examples of conflict between helping family and 
Table 2. Paragraphs attesting to the moral valence of cooperation

\begin{tabular}{lcc}
\hline & Positive & Negative \\
\hline Helping kin & 214 & 0 \\
Helping group & 127 & 0 \\
Reciprocating & 151 & 0 \\
Being brave & 101 & 0 \\
Respecting superiors & 133 & 0 \\
Dividing resources & 17 & 0 \\
Respecting property & 218 & 1 \\
\cline { 2 - 3 } Total & 961 & 1 \\
\hline
\end{tabular}

Most of these positively morally valenced cooperative behaviors were observed in most societies (see table 3 and figure 2). The average number of behaviors observed per society was: mean $=4.4, \mathrm{SD}=1.5$, median $=5$, mode $=5.5$ $($ minimum $=1$, maximum $=7)$. A repeated-measures general linear model (with Bonferroni correction for multiple comparisons) revealed that there were significantly more societies in which "property" was observed than "bravery," "respect," and "fairness" ( $P$-values $\leq .001)$; and there were significantly fewer societies in which "fairness" was observed than all other types of moral behavior $(P$-values $\leq .001)$. All other differences were nonsignificant. There were no societies in which any of the seven cooperative behaviors had a negative moral valence. (The "exception" reported above was itself an exception-seven other paragraphs attested to the positive moral valence of property among the Chuuk).

When aggregated by cultural region, all seven positively morally valenced cooperative behaviors were observed in all six regions - with the sole exception of "dividing disputed resources" in Central America (for which there were no data). ${ }^{12}$ Crucially, the positively morally valenced cooperative behaviors were observed with equal frequency in all regions: oneway ANOVAs revealed no significant difference between regions (all $F$-statistics $\geq 0.5$ and $\leq 1.28$, all $P$-values $\leq .78$ and $\geq .29$ ).

\section{Discussion}

A survey of 60 diverse societies found that the moral valence of seven cooperative behaviors was uniformly positive. In every society for which there were data, these seven cooperative be-

helping group; two of conflict between helping family and being brave; two of conflict between helping family and deferring to authority; and one example each of conflict between helping family and reciprocating, helping group and being brave, reciprocating and being brave, being brave and being deferential, and being deferential and respecting possession. However, in these cases, the moral values were portrayed as being in conflict, rather than one being good and the other bad.

12. As noted above, although there were several accounts of individuals in Central America "dividing resources equally" and contributing their "fair share," these were not sufficiently specific to be counted as "fairness" under our strict coding procedures. haviors were considered morally good. There were no counterexamples, that is, societies in which these behaviors were considered morally bad. The survey also found that these cooperative morals were widespread-with most appearing in most societies - and that they were observed with equal frequency across all cultural regions.

As such, these results provide strong support for the theory of morality-as-cooperation, and no support for the more extreme versions of moral relativism. In short, Hume was right, and Locke was wrong. When you "look abroad into the several tribes of men" there are some widely held morals that are not elsewhere "slighted or condemned," and they include precisely those morals predicted by morality-as-cooperation. As Hume (1748) put it: "history informs us of nothing new or strange in this particular." By way of illustration, "the moral values reinforced during traditional Amhara adolescence... [include] ... the importance of loyalty to kin" (Levine 1965:134), and "flouting kinship obligation is regarded as a shameful deviation, indicating an evil character" (Messing and Bender 1985:247). In Korea, there exists an "egalitarian community ethic [which includes the values of] mutual assistance and cooperation among neighbors [and] strong in-group solidarity" (Brandt 1971:25). "Reciprocity is observed in every stage of Garo life [and] has a very high place in the Garo social structure of values" (Majumdar 1978:138). "Those who cling to warrior virtues are still highly respected" among the Maasai; "the uncompromising ideal of supreme warriorhood [involves] ascetic commitment to self-sacrifice . . . in the heat of battle, as a supreme display of courageous loyalty" (Spencer 1988:131). The Bemba exhibit "a deep sense of respect for elders' authority" (Maxwell 1983:63). The Kapauku "idea of justice" is called "uta-uta, half-half . . . [the meaning of which] comes very close to what we call equity" (Pospisil 1958:287). And "respect for the property of others is the keystone of all interpersonal relations" among the Tarahumara (Fried 1951:167). As such, and in the absence of any counterexamples, these seven forms of cooperative behavior remain plausible candidates for universal moral rules.

When interpreting these results, two considerations should be kept in mind. First, the ethnographic source material analyzed here was not originally collected to test morality-ascooperation's hypotheses, and hence the moral valence of cooperative behavior was recorded somewhat serendipitously (if at all). As such, it is likely that our results are an underestimate of the cross-cultural prevalence of these moral valuesabsence of evidence is not evidence of absence. Indeed, there was a positive correlation between observed moral values and the total number of paragraphs describing that society in the HRAF archive $(r=0.43, P=.001)$. This suggests that much of the variation in observed morals per society can be attributed to variation in the ethnographic coverage of that society; had there been more information on a given society, we would likely have observed more of the seven moral values more frequently.

Second, methodological details to do with the categorization and coding of the moral domains may have introduced some 


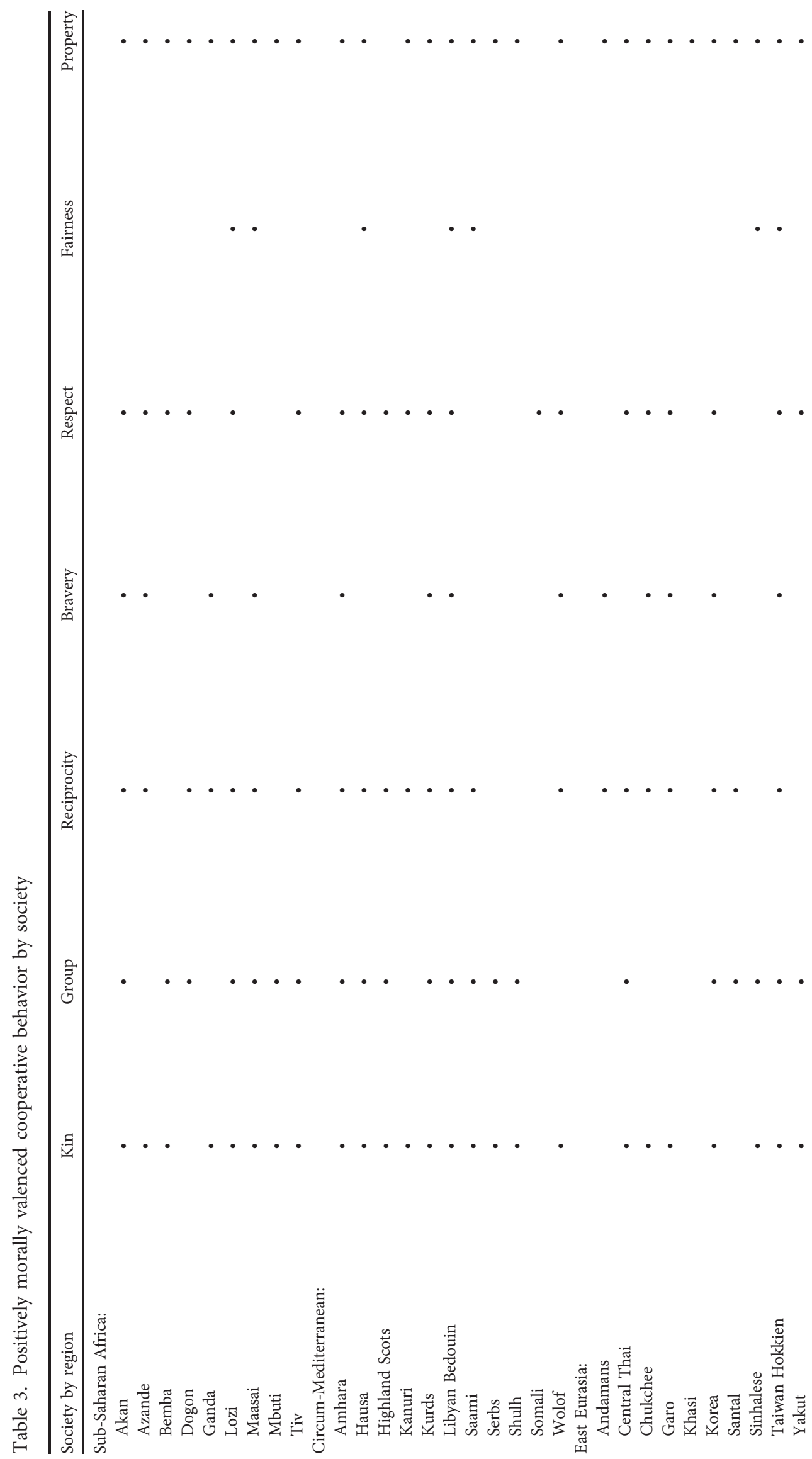

56

This content downloaded from 163.001.203.194 on February 10, 2020 04:04:08 AM 


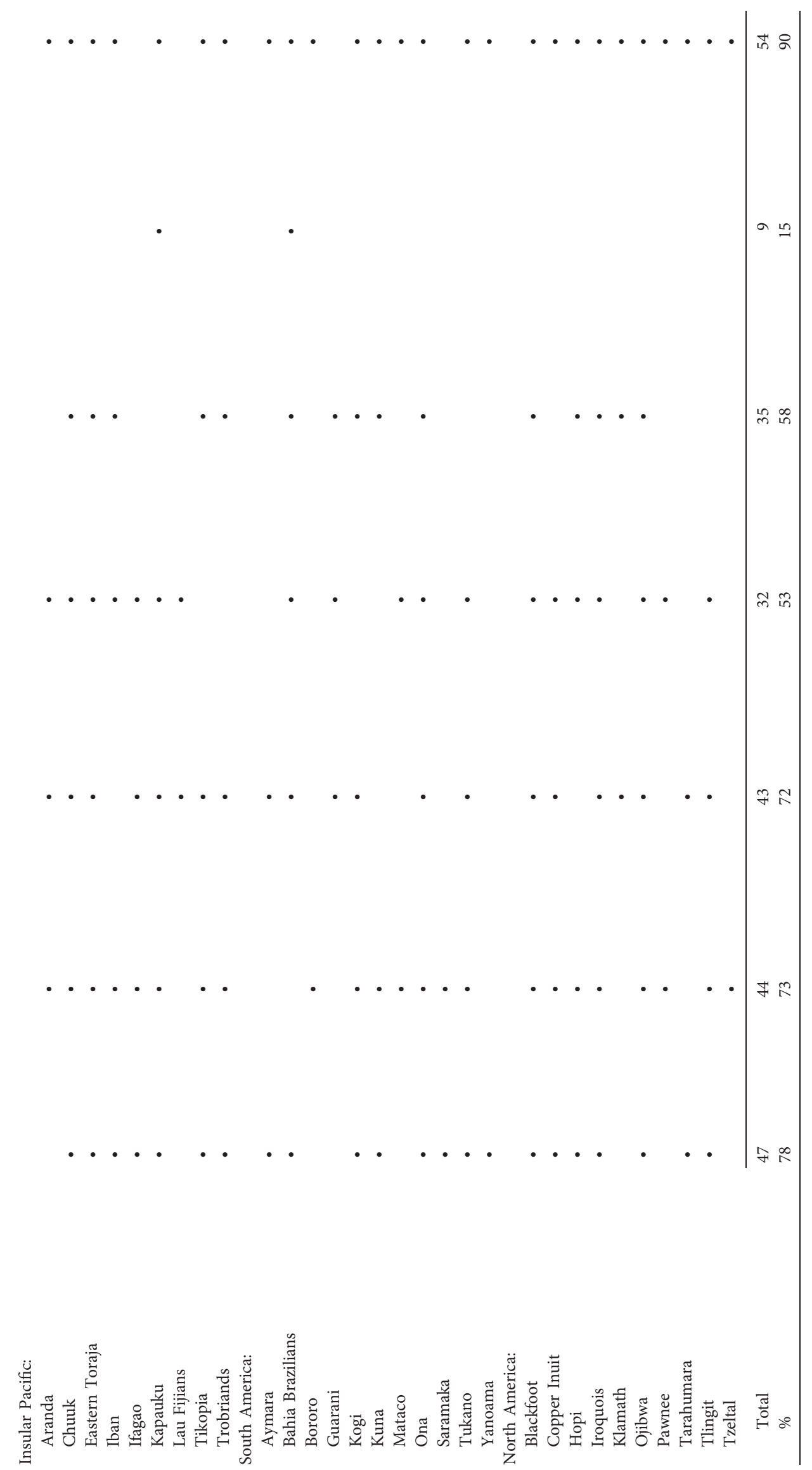

57

This content downloaded from 163.001.203.194 on February 10, 2020 04:04:08 AM 


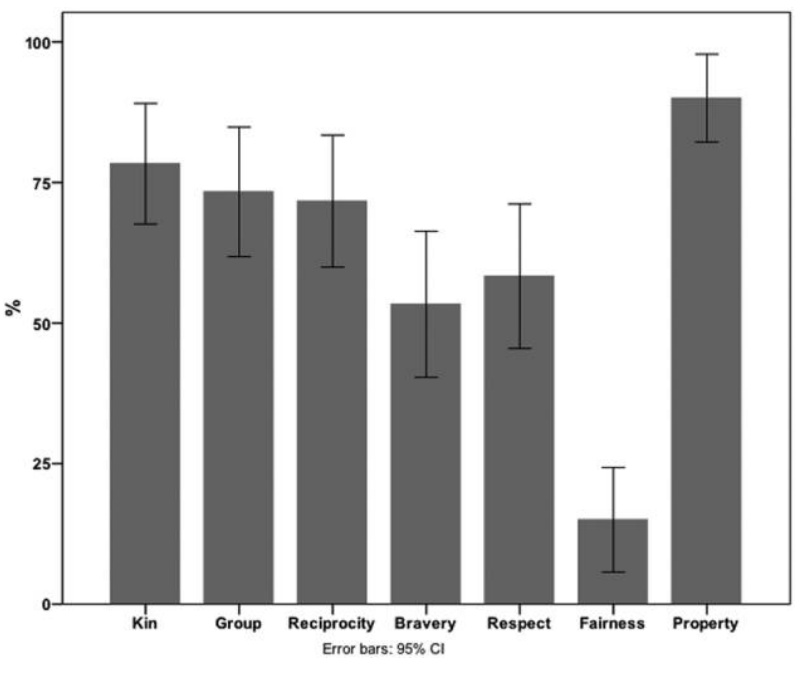

Figure 2. Percentage of societies in which positively morally valenced cooperative behavior was observed.

artifacts into the data that partly explain why some morals were observed more frequently than others, and why some were relatively rare. Some coding categories focus on one of several possible solutions to a problem; and the more solutions there are, the lower we should expect the frequency of any one of them to be. For example, as noted above, hawkishness can be displayed not only by bravery but also by other costly signals such as generosity (and other conspicuous displays of wealth), which may partly explain why "bravery" was relatively rare. And some coding categories were broader than others, capturing a wider variety of behaviors, which may have skewed the apparent frequency of a moral value. For example, there are many ways to "help kin," but only one way to "divide resources to forestall a dispute" - this may partly explain why "family values" were very common and "fairness" was relatively rare. Similarly, although "property rights" were present in nearly all societies, there appeared to be considerable variation in who (males, females, children, chiefs) could own what (land, movable property, each other), and had we attempted to code for these smaller, more specific categories, the frequency of any given trait would have been lower.

And of course, the present study has its limits. First, the study investigated the moral valence of only seven cooperative behaviors - it did not investigate the moral valence or prevalence of the other cooperative traits encompassed by moralityas-cooperation (such as forgiveness or generosity). And it remains to be seen whether the theory can be extended to provide cooperative explanations of other moral phenomena, including those encountered in this ethnographic reviewindustry and laziness, truth-telling and honesty, chastity and fidelity, hospitality and gossip, the virtues expected of a leader, some forms of purity, and the behavior expected by gods, spirits, and ancestors.

Second, the present study employed a sample of 60 cultures to minimize "Galton's problem" of the nonindependence of cross- cultural data points. Hence this review cannot exclude the possibility that there are other societies - beyond these 60 - that have moral values that provide counterexamples that refute the theory. Nor does the selected sample of 60 cultures completely solve the problem of nonindependence of cross-cultural data points (Ember and Otterbein 1991).

Third, the nature of the source material meant that we were able to code only for the (binary) presence or absence of the cooperative moral; we were not able to measure within- or between-society variation in how strongly these various moral values were held or endorsed, or how conflict between these different moral values was resolved. As such, we were not able to test morality-as-cooperation's further prediction that, far from being identical, moral systems will vary as a function of variation in the value of different types of cooperation under different conditions - in other words, to the extent that individuals (or societies) face different cooperative problems, and benefit from different solutions, they will prioritize different moral values (Curry 2016). Consistent with this view, our impression of the source material was that, even if all societies shared the same moral values, they varied in how they prioritized or ranked them. In some societies, family appeared to trump group; in other societies it was the other way around. In some societies there was an overwhelming obligation to seek revenge; in other societies this was trumped by the desire to maintain group solidarity. And of course our study found that moral obligations to members of one's family, one's group, and to senior members of one's hierarchy were relatively frequent, but (positive) reciprocity and fairness were relatively rare. Morality-as-cooperation would predict that this was partly because, in our sample of societies, cooperative interactions with kin and group and high-status individuals occurred more frequently (or conferred greater benefits) than cooperative interactions with anonymous, mobile strangers of equal status. ${ }^{13}$ But further research will be needed to test this conjecture.

To overcome these limitations, future work should aim to investigate the moral valence of a wider range of cooperative behaviors, in more societies, using more sophisticated methods. Theorists should mine the game theory literature to look for further accounts of cooperation that could perhaps explain further aspects of morality, and they should investigate whether the cooperative approach can be extended to as yet undertheorized aspects of morality such as sexual, religious, and political ethics (McKay and Whitehouse 2014). Ethnographers should employ new statistical techniques, including multiple imputation and two-stage instrumental variables regression, that now make it possible to overcome Galton's problem at the analysis stage (Brown and Eff 2010; Eff and Dow 2009) and

13. More generally, morality-as-cooperation has the potential to explain the historical shift "from status to contract" in social relations (Maine 1861), as well as the more recent observations of a division between "communal" and "contractual" values (Schwartz 1992) and between "binding" and "individual” moral foundations (Graham et al. 2011). 
thereby potentially test morality-as-cooperation against eHRAF's full sample of approximately 200 ethnographically attested cultures. ${ }^{14}$ And psychologists, anthropologists, and historians should also investigate the relationship between particular moral values and the corresponding individual- and societallevel indicators of cooperation - such as family size and dispersal, group size, mobility, subsistence strategy, reliance on trade, frequency of warfare, degree of inequality, political structure, age structure, resource base, and territory size (Gelfand et al. 2011; Turchin et al. 2012; Turchin et al. 2015). These predictions could be further tested by gathering new data on the full range of moral values, using survey and questionnaire methods, from representative cross-cultural samples (Curry, Jones Chesters, and Van Lissa 2019). Such work would help to move the debate on from arguing about whether or not morality varies, to explaining precisely how and why it varies, and thereby steer a middle way between the extremes of unbending moral absolutism and anything-goes moral relativism, and toward a more theoretically nuanced, and empirically tractable, view of moral variation (for one such example, see Wong 2006).

\section{Conclusion}

We have shown how morality-as-cooperation, through the use of game theory, exhibits a theoretical precision and explanatory scope that supersedes that of previous cooperative accounts of morality. And we have shown how one of the theory's central predictions - that cooperation is always and everywhere considered moral - is supported by an extensive cross-cultural survey of moral values. As such, we have removed two major obstacles to the theory's wider adoption. Thus, we recommend morality-as-cooperation to the field, and encourage fellow anthropologists to join us in testing its many further implications.

\section{Acknowledgments}

This work was supported by a Large Grant from the United Kingdom's Economic and Social Research Council (REF RES-060-25-0085) entitled "Ritual, Community, and Conflict" (to O.S.C. and H.W.) and an award from the John Templeton Foundation entitled "Axial-Age Religions and the Z-Curve of Human Egalitarianism.” (to D.A.M. and H.W.), an Advanced Grant from the European Research Council under the European Union's Horizon 2020 Research and Innovation Program (grant agreement No. 694986 to H.W.), and an award from the Templeton World Charity Fund entitled "Cognitive and Cultural Foundations of Religion and Morality" (to O.S.C. and H.W.). We thank Arran Davis, Cesca Hill, Susan Moore, Ben Mullins, and especially Martha

14. Larger numbers of societies per region would also make statistical tests of cross-regional variation more powerful.
Newson for research assistance. We thank Rosalind Arden, Helena Cronin, Matthew Jones Chesters, Darragh Hare, and the reviewers at Current Anthropology for providing critical feedback. We thank Roberto Andorno, Ashar Awan, Pradeep Chakkarath, Andrew Churchill, Bill Johnson, Marc Kilgour, Steven Pinker, and Lara Pourabdolrahim for supplying references and responding to queries. And we thank Helena Cronin, Darragh Hare, Mark Alfano, Caspar J. Van Lissa, Max Krasnow, and Samuel Mehr for providing critical feedback on our reply.

\section{Comments}

\section{Paul Bloom}

Department of Psychology, Yale University, PO Box 208205, New Haven, Connecticut 06520, USA (paul.bloom@yale.edu). 15 III 18

Morality is ultimately about fairness and justice. Or it is about maximizing the welfare of sentient beings. Or intertemporal choice, giving up immediate satisfaction for long-term gain. Or maybe it is really all about altruism. Morality has one foundation-harm. Or it has three foundations: autonomy (which includes harm), but also divinity and community. Or five foundations: care, fairness, loyalty, authority, and purity. Or perhaps six - do not forget about liberty. Morality is innate and universal, a modular system of the sort proposed by Chomsky and Fodor for language. Or it is innate and universal, but nothing like a modular system. Or it is partially innate and partially learned. Or entirely learned. At least we know that morality is a distinct domain, a cognitive natural kind. Unless it is not.

Each view is defended by contemporary scholars. I have my own dogs in these fights (see, e.g., Bloom 2013), but it is fair to say that nobody yet knows which views, if any, are correct.

This valuable paper adds a lot to these debates, defending the position that morality consists of solutions to the problems of cooperation that emerge in social life. Looking at 60 cultures, Curry, Mullins, and Whitehouse find that seven forms of cooperative behavior - helping kin, helping your group, reciprocating, being brave, deferring to superiors, dividing disputed resources, and respecting prior possession-are always seen as morally good. They conclude that this favors their morality-ascooperation theory as a unified account of morality. As they are careful to point out, they are not the first to see cooperation as central; to take just one example, Haidt (2012), claims that the purpose of morality is "to suppress or regulate self-interest and make cooperative societies possible" (202). Still, the crosscultural data are original and important, and this paper deserves a lot of attention.

It has its limits, though. This is not a psychological theory. The authors say nothing about the proximate mechanisms through which we come to have moral judgments; they say 
nothing about the role of reason and the emotions; nothing about brain structures, social forces, or development. They claim that moral judgments are universal due to multiple forces working together - a "collection of instincts, intuitions, inventions, and institutions." But they makes no specific claims about what's innate, what's learned, and what arises from personal choice.

This left me uncertain as to what would falsify their theory. Suppose we found a society where, say, respecting prior possession was not seen as morally good. Would this be a problem for the morality-as-cooperation theory? Would it make a difference if all the members of the society were 2-year-olds? I have utilitarian friends who argue that the bonds of kinship have no special moral weight; and there are communities of anarchists who would reject the ethics of deferring to your superiors. Are these quirky moral views problems for the theory, or can we put them aside?

One important component that's missing is that we're never told why these behaviors are thought to be moral. When doing their study, the authors looked at whether each behavior was "described as good, right, moral, ethical, or virtuous, or as an obligation, duty, or moral norm, and so on" - and this makes perfect sense. But why is cooperation related to notions such as virtues and obligations and duties? Why is not it simply positive, in the same way that most of us find ice cream positive? (See Stanford 2018.) To put the point differently, all sorts of creatures cooperate with one another and respond differentially to the cooperative and noncooperative behavior of others. But rats and dogs presumably do not have notions such as right, moral, ethical, and so on. This means that the demands of cooperation are not sufficient to explain the emergence of morality.

Finally, to show that morality-as-cooperation is correct, it is not enough to show that we moralize cooperative behavior. We also have to show that we do not moralize other sorts of behavior. And, actually, the category of morality is bigger than cooperation. We care a lot about the treatment of the dead, for instance. (Is there a culture where people are entirely indifferent to what you do with the corpse of a loved one?) And, as the authors concede, we care a lot about sex. There is no culture in the world where the people are morally indifferent toward behaviors such as masturbation, homosexuality, bestiality, rape, and infidelity.

Many scholars, including myself, see much of the morality of sex as a biological accident-essentially a misappraisal of disgust reactions that have evolved for different purposes (Bloom 2004, 2013) —-whereas others believe that the morality of sex ultimately reflects intuitions about harm, including selfharm (e.g., Gray, Schein, and Ward 2014). But a cooperationbased account seems like a nonstarter here. When people get outraged at a man caught having sex with a pig, it is hardly plausible that they are upset that he's a bad cooperator!

Or, as a simpler case, consider hitting. I am not a cultural anthropologist, but my intuition is that if you go to a community anywhere in the world, walk up to someone, and punch them in the face, you will have a lot to answer to. Hitting someone is a foundational moral violation. Mikhail (2011) argues the act of intentionally striking someone without their permission - battery-has a special immediate badness that all humans respond to. Indeed, these sorts of physical infractions are found to be morally wrong by the youngest babies we can test (Bloom 2013). This might be at core of morality, as opposed to more subtle and later developing capacities such as valuing bravery or respecting the possessions of others.

\section{Herbert Gintis}

Santa Fe Institute, 1399 Hyde Park Road, Santa Fe, New Mexico 87501, USA (hgintis@comcast.net). 18 IV 18

\section{Universal Principles of Human Morality}

In a marvelously ambitious and widely useful article, Curry, Mullins, and Whitehouse validate a morality-as-cooperation model of the communality of moral principles across 60 societies. These common principles include helping kin, helping and being loyal to one's group, exhibiting positive and negative reciprocity, being brave, compromising with others, being fair, and respecting property rights. This study strongly supports the analysis of Samuel Bowles and myself in our recent book (Bowles and Gintis 2011) and my recent Current Anthropology article (Gintis, van Schaik, and Boehm 2015) on the evolutionary origins of human political behavior.

My basic point is that society is a game with rules, people are players in this game, and politics is the arena in which we affirm and change these rules. Unlike the rules in standard game theory, however, social rules are continually subject to change as the material and environmental conditions for survival change. The distinctiveness of human social life flows from the fact that we construct and then play social games. Other animals are playful and have rules that govern their social life. But other animals do not make up the games they play. They do not change the rules of the game to suit their purposes. Similarly, other animals live in societies. But the rules of the game for nonhuman societies are inscribed in the genome of the species, whereas ours are not.

Playing games with socially constructed rules requires a moral sense. People gain satisfaction by playing by the rules, are ashamed when they break the rules, and are offended when others break the rules. Indeed, individuals often reward others who play by the rules and punish others who break the rules even at considerable personal cost and without a prospect of personal return in the future. This is why the results of Curry, Mullins, and Whitehouse are so important: a cooperative act invites material and psychic rewards from others, even from others who may not be involved with or gain from the act.

The emergence of cooperative breeding in the hominin line (Hrdy 2000), together with environmental developments that 
made a diet of meat from large animals adaptive, as well as cultural innovations in the form of fire, cooking, and lethal weapons, created a niche for hominins in which there was a significant advantage to individuals with the ability to communicate and persuade. These forces added a unique political dimension to human social life that, through gene-culture coevolution, became Homo ludens - Man, the game player.

Strong social interdependence plus the availability of lethal weapons in early hominin society undermined the standard social dominance hierarchy, based on pure physical prowess, of multimale/multifemale primate groups, characteristic, for instance, of chimpanzees. The successful political structure that ultimately replaced the ancestral social dominance hierarchy was an egalitarian political system in which the group controlled its leaders. Group success depended both on the ability of leaders to persuade and motivate, and of followers to submit to a consensual decision process. The heightened social value of nonauthoritarian leadership entailed enhanced biological fitness for such traits as linguistic facility, political ability, and indeed for human hypercognition itself (Gintis 2016).

The most plausible hominid development leading to morality as cooperation, paradoxically enough, was the emergence of lethal weapons (Bingham 1999). Lethal weapons, developed for hunting game, could be used to carry out collective punishment against norm violators, thus radically lowering the cost of punishing transgressors. More important was the fact that any man could kill any other, for example, in his sleep or when caught off guard, so the traditional hominid political hierarchy based on the pure physical prowess of the alpha male was shattered. The pieces were picked up through the growth of political structure based on the persuasive skills and intelligence of individuals who vied for group leadership and were rewarded not by arbitrary power but by enhanced biological fitness (Boehm 1999).

In sum, our primate ancestors evolved a complex sociopolitical order with cultural innovation in the domestication of fire and of collective child rearing. This created a niche for hominins in which there was a high return to coordinated, cooperative, and competitive scavenging. This development was accompanied by the likely use of clubs, spears, and longrange projectiles as lethal weapons.

Hominin society increasingly required sophisticated coordination of collective action, the critical reliance on resources produced by cooperative hunting, and procedures for fair sharing. Lethal weapons helped to stabilize this system because it undermined the tendencies of dominants to exploit others in society. Thus two successful sociopolitical structures arose to enhance the flexibility and efficiency of social cooperation in humans. The first was the reverse dominance hierarchy, through which leaders were kept weak and their reproductive success depended on an ability to persuade and motivate, coupled with the rank-and-file ability to reach a consensus with such leadership. The second was cooperative child rearing and hunting, which provided a strong psychological predisposition toward prosociality and favored internalized norms of fairness.

\section{Kristopher M. Smith and Robert Kurzban}

Department of Psychology, University of Pennsylvania, 3720 Walnut Street, Philadelphia, Pennsylvania 19014, USA (kurzban@psych .upenn.edu). 12 IV 18

\section{Morality Is Not Always Good}

Morality-as-cooperation (MAC) proposes that morality is a suite of biological and cultural solutions to cooperative problems in social interactions. Drawing on insights from non-zero-sum games, the authors argue that there are a set of universal norms that lead individuals to pursue mutually beneficial outcomes in a variety of contexts. We, in contrast, argue that morality often reduces aggregate outcomes, prohibits behaviors unrelated to cooperation, and is used by individuals to further their own selfinterest.

According to MAC, moral dilemmas arise when a cooperative behavior conflicts with another cooperative behavior, requiring a trade-off to be made. This predicts that "the only time a form of cooperative behavior will be considered morally bad will be when it is pursued at the expense of some other larger form of cooperation." Yet moral cognition is nonconsequentialist; people frequently do not consider trade-offs when making moral judgments and condemn behaviors that violate norms even when they lead to aggregate better outcomes (DeScioli and Kurzban 2009). The most prominent example is the trolley problem (Foot 1967); people judge sacrificing one person to save five other people as impermissible (Mikhail 2007). Here, saving five lives is a larger form of cooperation than not killing one person; the best non-zero-sum outcome would be for people to sacrifice the one person. Compare this to the burying beetle, which will kill some of its own offspring and feed the bodies to the remaining larvae (Mock 2004). Natural selection solved the problem of helping kin in the burying beetle by designing a decision-making system that sacrifices some kin to save others. Interestingly, people do say they are more willing to kill one sibling to save five siblings than they are to kill one stranger to save five strangers, yet they judge the two acts to be equally morally impermissible (Kurzban, DeScioli, and Fein 2012). This indicates that morality and kindirected cooperation are opposing forces.

Many moral norms across societies have nothing to do with social interaction, and many of these norms produce negative, even fatal, outcomes. Consider the norm in India that prohibits the killing or eating of cows. Because of this norm, the cow population has overgrazed, starving people and cows alike (Fox 2003). This norm in no way polices social interactions related to cooperation, and it causes immense suffering; morality is such a strong, insidious force that people would rather starve to death than violate the norm.

To take another example, consider the prohibition against people selling their own organs, such as kidneys. This prohibition prevents people from reaching mutually beneficial (cooperative) arrangements, and leads to tangible losses (Barnieh et al. 2013). Some evidence suggests concerns such as undue or unjust inducement or the crowding out of altruistic donations 
are inflated (Allen and Reese 2013). In fact, the only opposition to kidney sales not possible to rule out is that the human body has an intrinsic, sacred value that cannot be bought. Notably, concerns of coercion or reduced altruism would be examples of uncooperative behavior explained by MAC, yet these are not the reasons people oppose kidney sales. It is the sacred, inviolable value of the human body, and not the outcomes, that drives opposition to financial incentives for organ transplants, despite the suffering that results from such prohibitions. Similar rules prohibiting consensual, mutually beneficial behaviors abound across cultures, and many of these norms are similarly destructive.

There is also variability within cultures of endorsement of various norms, and this variation is often predicted by selfinterest. This is particularly the case for norms that have nothing to do with cooperation. For example, monogamous individuals who invest much of their resources into a single relationship are more likely to oppose recreational drug use than promiscuous individuals (Kurzban, Dukes, and Weeden 2010). This may be because drug use is associated with promiscuity, and by cutting down on behaviors associated with promiscuity, monogamous individuals can prevent the costs associated with mate poaching. For similar reasons, monogamous individuals are more likely to oppose to gay marriage, particularly among those who associate homosexuality with promiscuity (Pinsof and Haselton 2016). These norms against recreational drug use or homosexuality are not relevant to cooperation, yet people use these norms to advance their own self-interest, often at a cost to others.

Even with norms that do police cooperation, people endorse specific versions that benefit themselves. For example, fairness norms could prescribe equality, in which resources are redistributed regardless of input, or equity, in which resources are redistributed proportional to contributions. In one experiment, people played an economic game in which they worked to earn an endowment. The first player did three times the amount of work of the second player, and the first player decided how to split the endowment; the player could choose to split it evenly between the two of them or split it such that the first player received three times as much as the second player. When asked how moral and fair each split was, the first player thought the equitable split was more fair, whereas the second player thought the equal split was more fair (DeScioli et al. 2014). In short, each player favored the particular fairness rule that benefited himself or herself.

It is of course the case that many moral norms across cultures do indeed police behavior relevant to cooperation, and many times these norms do so in ways that encourage better outcomes for all involved. Yet many norms are also irrelevant to cooperation and produce worse outcomes for all involved. Further, even when norms do police cooperation, people favor rules that are beneficial to themselves, not those that are mutually beneficial. So, although morality can facilitate and enhance cooperation, it can also be selfish and destructive. Understanding the evolution of morality will require dealing with both sides of the moral coin.

\section{David B. Wong}

Department of Philosophy, Duke University, 211 W Duke Building, Durham, North Carolina 27708, USA (d.wong@duke.edu). 25 III 18

Curry, Mullins, and Whitehouse provide a systematic articulation of the theory that morality is a collection of biological and cultural solutions to problems of cooperation. They identify seven forms of cooperative behavior that their theory predicts will be regarded as morally good across societies. They conclude, with some important qualifications about the limitations of their data set, that the theory is confirmed by a body of ethnographic data from 60 societies.

This commentary will primarily concern the conceptual setup of the theory, with some remarks on the theoretical implications of the data for that setup. There is a strong case for holding that a core function of morality is to foster and structure social cooperation. However, another related but distinct function for morality may be fostering and regulating intrapersonal coherence of motivation through presentation of ideals of character and of the fulfilling and worthwhile human life (Wong 2006). The two functions are related because social cooperation requires an ordering of potentially conflicting motivations within the individuals who are cooperating. It is no accident that ideals of the good human life often emphasize relationship with others: an evolutionary adaptation enabling human beings to cooperate may be the disposition to find relationship with others satisfying for their own sake (Moll et al. 2006; Tomasello 2016). However, the intrapersonal function is distinct because moral ideals of worthwhile human life can require more or other than whatever serves cooperation. An interesting question, for example, is whether the authors' schema of seven valued cooperative behaviors can accommodate what is often held to be the moral value of autonomy, which includes freedom, within limits, to pursue one's conception of a worthwhile human life.

The authors' main objection against Graham and Haidt's moral foundation of purity is that it is not related to cooperation. In contemporary developed societies, however, some believe that certain expressions of sexuality are moral perversions, whether or not there is an impact on nonconsenting others. This looks like a case of purity entering into their conceptions of morality. Furthermore, ideals of the worthwhile life sometimes contain an aesthetic dimension that is not reducible to helping make cooperation work. The Confucian appreciation of various rituals is of this nature. Conventionalized ways of greeting others, of taking meals with them, and of marking major life passages such as birth, coming of age, marriage, death, and mourning are admired when their performance shows a degree 
of mastery, spontaneity, and gracefulness. The line between the aesthetic and socially functional is blurred in this case. Rituals are valued as expressions and enactments of socially important attitudes such as concern and respect, but they are also appreciated for their beauty as well. Later in their paper, the authors do seem to allow for the possibility that some moral phenomena may not be explicable through the cooperation function: "industry and laziness, truth-telling and honesty, chastity and fidelity, hospitality and gossip, the virtues expected of a leader, some forms of purity, and the behavior expected by gods, spirits, and ancestors." This theoretical modesty seems appropriate.

One important issue posed by the authors' conclusions is how to explain the variance in greater frequency of occurrence of the different cooperative behaviors: there are significantly more societies in which property is observed than bravery, respect, or fairness, the latter being the least frequently observed. One possible explanation the authors present is variation in the extent and depth of the ethnographic data for different societies. Perhaps more complete data for some societies will reduce the variation. Another possible explanation is the way the cooperative forms are categorized and coded, with some forms more than others admitting a variety of ways they can be fulfilled. A third explanation is that different societies, because of their different circumstances and perhaps stages of development, will focus on different types of cooperative forms because these forms are suited, or at least thought to be suited, to the local circumstances. It is a serious possibility that none of the above strategies will fully explain all existing variation. It may be that the very concept of "cooperation" is too indeterminate and broad in content to allow for sufficiently fine-grained judgments as to which forms of cooperation are most appropriate to a given set of conditions. Culturally evolved and even biologically based behaviors may become prevalent due to a contingent set of factors that do not justify those forms as better promoting or sustaining cooperation.

Moreover, the authors observe that they "were not able to measure within- or between-society variation in how strongly these various moral values were held or endorsed, or how conflict between these different moral values was resolved." From a philosophical, normative perspective on how conflicts between moral values are to be resolved, it is not at all apparent that a conceptual framework exists that justifies uniquely correct resolutions of all serious conflicts of values. Conflicts between duties to family and duties to uphold public justice are commonly recognized in the moral and literary texts of different societies: the conflict experienced by Antigone between her duty to bury the body of her brother and King Agamemnon's order that the body of a traitor not be buried; Confucius's declaration that a son is not to bring to authorities his father's theft of a sheep (Analects 13.18) versus the later Confucian philosopher Xunzi's declaration that a son is to follow righteousness, not his father, in case of conflict (Xunzi, chap. 29, "The Way of the Son"). Further, societies may very well vary in the extent to which they emphasize the importance of autonomy versus duties to family and the group, or even to the welfare of humanity at large. This is why pluralism, and neither extreme relativism or strict universalism, may be the most viable conclusion. The authors deserve much credit for bringing the field closer to the right questions to ask.

\section{Reply}

Morality-as-cooperation (MAC) is the theory that morals are solutions to the problems of cooperation recurrent in human social life. There are many such problems, hence many different solutions, including helping one's family, helping one's group, returning favors, displaying hawkish and dovish traits, sharing equitably, and respecting prior ownership. In the present paper we test the most straightforward prediction of the theory - that "if morals are what we call solutions to problems of cooperation, then these solutions will be called moral"-using ethnographic accounts of the ethics of 60 societies. And we find that, as predicted, these cooperative traits are indeed considered morally good all around the world.

We are grateful to the commentators for their thoughtful responses to the paper, and to Current Anthropology for providing a forum in which to address them. We are glad that, for the most part, the commentators welcome the contribution that our findings make to ongoing debates about the nature of morality, and that our work is consistent with much previous research in the field (Gintis). However, we note that the commentators also raise important questions about the underlying theory. Below we offer some preliminary answers.

Bloom questions whether MAC is a "psychological theory," and doubts whether it has anything to say "about the proximate mechanisms through which we come to have moral judgments." In response, we would argue that MAC is a higher level theory about the function of morality from which predictions about psychological and other proximate mechanisms can be, have been, and are being derived.

For example, MAC predicts that, because there are many types of cooperation, there will be many types of morality; and it predicts that these types will include the seven listed above. MAC predicts that each of these types of cooperation will be regarded as morally relevant - that is, as falling within the moral domain - giving rise to specific moral domains dedicated to family, groups, reciprocity, heroism, deference, fairness, and property. MAC also predicts that, because the value of these different types of cooperation can vary independently, moral values in each domain will vary independently too. Hence moral values will exhibit a multifactorial structure, varying on these seven dimensions. All of these predictions have been tested and supported (Curry et al. 2019). Further research will be needed to test the subsequent prediction that individual (and cultural) differences in moral values will reflect the value 
of cooperation at different stages of development (Curry 2005:182; Sheskin et al. 2014), and under different social conditions.

MAC also predicts that behavior not tied to a specific type of cooperation will not constitute a distinct moral domain. For example, MAC predicts that harm - including "hitting someone" and "intentionally striking someone without their permission" - is not a foundational moral violation. Instead, the moral valence of harm will vary according to the cooperative context: uncooperative harm (battery) will be considered morally bad, but cooperative harm (punishment, self-defense) will be considered morally good, and competitive harm in zero-sum contexts (some aspects of mate competition and intergroup conflict) will be considered morally neutral — "all's fair in love and war." Thus cooperation explains the conditions under which "harm" is, and is not, justified. Similarly, MAC predicts that "disgust" - the avoidance of potential pathogens - is not a foundational moral domain. Rather, disgust is moralized only when employed to solve a cooperative problem. This includes regulating behavior that puts other people at risk of infectionpublic health hazards like the disposal of corpses - and extends to other cooperative problems for which "avoidance" is part of the solution. These problems may include avoiding inappropriate sexual partners (as in incest); expelling "ideologically impure" heretics from the body politic; containing bad behavior that is copied, and spreads like a contagion (Jones and Jones 2000); avoiding cheats by "walking away" (Aktipis 2011; Jeon, Kim, and Choe 2016); and distancing oneself from low-status activities or people (e.g., "unclean" castes). By contrast, disgust responses in noncooperative situations, like avoiding rotten food, are not part of the moral domain. Thus cooperation explains the conditions under which "disgust" is, and is not, moralized. Further research will be needed to test these predictions.

Furthermore, if we add to the functional theory the auxiliary hypothesis that there is at least some innate adaptive machinery underpinning moral thought and behavior (some of which we review in the paper), then MAC predicts that morality will be, at least in part, the product of multiple innate psychological adaptations for cooperation - as opposed to the view that morality is solely the product of a single more general "norm acquisition device" (Sripada and Stich 2006), the content of which is entirely learned (Prinz 2007; Sterelny 2010). If so, then we may make the further prediction that morality in each of these domains will be moderately heritable, and subserved by distinct genetic "common pathways" and brain structures. Tests of these predictions are under way. Only by integrating genetic and environmental approaches - including social constructionism (Gintis) - will we fully understand how moral culture is evoked and transmitted across time and place (Whitehouse 2016).

Bloom also asks whether MAC is falsified by cases in which these cooperative traits are not considered moral-for example, by utilitarians who do not recognize special duties to kin, or anarchists who disapprove of deference to superiors. We agree that these are interesting cases, which is why our survey methodology explicitly set out to find them. The fact that we did not find any suggests that such beliefs are not representative of the views of humanity as a whole, but are "outliers." How might MAC explain them? Are they just the tail ends of normally distributed moral beliefs? Are they more likely to occur among people who do not face the corresponding cooperative problem, for example, among people who have relatively few family commitments? Are they attempts to invent new morals, destined perhaps to fail precisely because they are not stable cooperative solutions? Or are they deemed immoral because they conflict with some other more valuable cooperative opportunities? Questions about how and why "philosophical" views of morality differ from "folk" views should be a focus of future research for MAC - similar to investigations in the cognitive science of religion into the differences between "theologically correct" religion and more intuitive folk variants (Barrett 1999; Slone 2004).

Bloom, Smith and Kurzban, and Wong also correctly point out that another way to falsify the theory would be to identify areas of morality that are not about cooperation. In particular, Bloom argues that "a cooperation-based account" is a "nonstarter" when it comes to explaining sexual morality, including prohibitions against "masturbation, homosexuality, bestiality, rape, and infidelity."

We agree that it remains to be seen whether MAC can explain all moral phenomena. And we agree that sexual morality in particular is at present undertheorized, and hence poorly understood. However, we hypothesize that, on closer inspection, many aspects of sexual morality will turn out to be the products (or by-products) of cooperative mechanisms. If morals are solutions to the problems of cooperation recurrent in human social life, then perhaps sexual morals are solutions to the problems of cooperation recurrent in human sexual life, and we should view sexual morality as cooperation about sex. As such, MAC predicts that cooperative sexual behavior will be regarded as morally good, and uncooperative sexual behavior will be regarded as morally bad. Candidate examples can be found across all seven of the cooperative domains we have identified. First, kinship. Inbreeding has deleterious effects on the reproductive success of close kin; this could explain why incest is regarded as morally wrong (Lieberman, Tooby, and Cosmides 2003). Second, mutualism. Men and women often "team up" to raise offspring, to the mutual benefit of all involved; this could explain why long-term committed relationships such as marriage are seen as morally good, and why short-term uncommitted relationships - involving premarital, or promiscuous sex - which threaten the stability of long-term relationships are seen as morally bad (Kurzban, Dukes, and Weeden 2010; Pinsof and Haselton 2017; Price, Pound, and Scott 2014). Third, reciprocity. Long-term relationships such as marriage often involve an exchange of sexual exclusivity for resources (Baumeister and Vohs 2004); this could explain why violating this sexual con- 
tract - through infidelity, adultery, cheating - is considered morally bad, and why "dads" who do not invest are seen as "cads" (Kruger, Fisher, and Jobling 2003). Fourth, hawkish traits. Humans can resolve conflicts over mates by displaying sexually selected mate-winning traits, rather than coming to blows (Curry 2007). This could explain why cues of high mate value among men (virility, bravery, generosity) and women (fertility, chastity, beauty) are considered virtues, and why cues of low mate value - such as masturbation and bestiality for men (suggesting an inability to attract a mate), and masturbation for women (a correlate of "unrestricted sociosexuality"; Penke and Asendorpf 2008) — are considered shameful vices. Fifth, dovish traits. In traditional societies, parents, elders, and other authority figures often arrange marriages; this could explain why defying their wishes (e.g., by eloping) is considered morally bad, and why punishing this defiance is considered by some to be "honorable." Sixth, fairness. Conflict over mates is also reduced by "sharing them out equally" (Henrich, Boyd, and Richerson 2012); this could explain why monogamy is regarded as morally superior to polygamy, and why divorce (serial monogamy) has been regarded as morally bad. Seventh, property rights. Conflict over mates is also reduced by respecting prior possession ("Hands off, he's mine!"); such "sexual proprietariness" could explain why "attracting someone who is already in a relationship" is referred to as "poaching" (i.e., "stealing"; Schmitt and Buss 2001), and why some types of sexual crimes (e.g., rape) have been treated as a form of theft (Wilson and Daly 1992). Thus MAC suggests that there is more to sexual morality than the "misappraisal of disgust," and instead derives from first principles testable predictions about moral attitudes to incest, marriage, infidelity, the sexual virtues, honor killings, monogamy, and mate poaching. MAC also predicts that individual and cultural variation in sexual morals will reflect the value of different types of sexual cooperation for different people under different conditions. Far from being a "nonstarter," MAC could mark the beginning of a productive new research program on sexual morality.

Similarly, Smith and Kurzban point to food taboos, specifically the prohibition against killing cows, as another candidate example of morality without cooperation. We are not so sure. Killing cows may be taboo because they are viewed as family (“'Gai hamari mata hai'- the cow is our mother!"), as symbolic markers of group identity, as deserving of gratitude for all they provide, or as hawkish signals of wealth and status ("artha"; Fox 1999). Analyzing these and other apparently anomalous moral beliefs-distinguishing their functional aspects from their functionless by-products - should be a goal of future research.

Bloom also argues that humans have the sense that morality is not merely subjective, but is instead objective and external (Stanford 2018); and he argues that this feature is not explained by cooperation: "the demands of cooperation are not sufficient to explain the emergence of morality." Stanford himself, however, makes the opposite case - that "moral externalization" is "a cooperation-building machine." If so, then "externalization" follows from, rather than contradicts, MAC. Moral judgments feel like they are related to an objective reality because cooperation is an objective reality (Curry 2005:125; Sterelny and Fraser 2016). Some things promote cooperation, and some things do not, whether we like it or not. And the demands of morality are imposed on us externally - by other people. Thus it is no surprise that would-be cooperators appeal to, and attempt to create a consensus about, these objective problems and solutions. Whereas, for individuals acting alone, subjective preferences suffice. Additional research on cooperation, including coordination and common knowledge, will help to shed further light on the psychology of externalization.

Wong argues that a "fulfilling and worthwhile human life" involves more than cooperation, and includes the contemplation of beauty and the exercise of autonomy. True, humans have a range of goals and values, only some of which are cooperative (and hence, according to the theory, moral). Some are uncooperative, some competitive, and some not social at all. The most fulfilling life would presumably involve achieving them all; and doing so may require a degree of autonomy - the freedom to pursue one's own interests, including the freedom from being coerced to join other people's cooperative schemes. Nevertheless, by retaining the distinction between cooperative and uncooperative goals, we retain the ability to distinguish between morally good and morally bad ways of living, however fulfilling each may be.

Finally, Smith and Kurzban raise as potential objections to MAC the fact that morals are self-serving, nonconsequentialist, often suboptimal, and sometimes destructive. True; but this too follows from, rather than contradicts, the theory. MAC's claim that morals are biological and cultural strategies for cooperation (as opposed to altruism) predicts that they will be (ultimately, genetically) self-serving, and that, given the choice of cooperative equilibriums, people will prefer those that benefit themselves the most. MAC also predicts that morals, qua conditional strategies, will resemble conditional rules, not open-ended consequentialist calculations - consistent with the standard view in evolutionary psychology that "individual organisms are best thought of as adaptation-executers rather than as fitnessmaximizers" (Tooby and Cosmides 1992:54). And MAC predicts that such strategies will not always be successful (let alone globally optimal), and will inevitably have some negative side effects - especially with regard to evolutionarily novel problems (e.g., organ transplants). As such, the pertinent question is not: "Do morals sometimes go wrong?" They do. Rather, the question is: "Do morals go wrong in ways that reflect the inevitable limitations and by-products of cooperative strategies, or is some other explanation required?" Answering this question is another important goal of future research.

In summary, by drawing on the mathematics of cooperation, MAC makes principled predictions about the nature of morality and its proximate instantiations that distinguish it from other theories in a crowded field. By testing these predictions, we will discover whether MAC provides what has been missing from 
anthropology and the behavioral sciences in general — a grand unified theory of morality.

-Oliver Scott Curry, Daniel Austin Mullins, and Harvey Whitehouse

\section{References Cited}

Aktipis, C. Athena. 2011. Is cooperation viable in mobile organisms? simple Walk Away rule favors the evolution of cooperation in groups. Evolution and Human Behavior 32(4):263-276.

Allen, M. B., and P. R. Reese. 2013. Financial incentives for living kidney donation: ethics and evidence. Clinical Journal of the American Society of Nephrology 8(12):2031-2033. [KMS/RK]

Altheide, David L. 1987. Reflections: ethnographic content analysis. Qualitative Sociology 10(1):65-77.

Alvard, M. 2001. Mutualistic hunting. In Meat-eating and human evolution. C. Stanford and H. Bunn, eds. Pp. 261-278. New York: Oxford University Press.

American Anthropological Association. 1947. Statement on human rights. American Anthropologist 49(4):539-543.

Atkinson, Q. D., and Harvey Whitehouse. 2011. The cultural morphospace of ritual form: examining modes of religiosity cross-culturally. Evolution and Human Behavior 32(1):50-62.

Axelrod, R. 1984. The evolution of cooperation. New York: Basic.

Balliet, Daniel, Junhui Wu, and Carsten K. W. De Dreu. 2014. Ingroup favoritism in cooperation: a meta-analysis. Psychological Bulletin 140:15561581.

Barnieh, L., J. S. Gill, S. Klarenbach, and B. J. Manns. 2013. The costeffectiveness of using payment to increase living donor kidneys for transplantation. Clinical Journal of the American Society of Nephrology 8(12):21652173. [KMS/RK]

Barrett, Justin L. 1999. Theological correctness: cognitive constraint and the study of religion. Method and Theory in the Study of Religion 11(4):325-339.

Barry, Herbert, III, Lili Josephson, Edith Lauer, and Catherine Marshall. 1976. Traits inculcated in childhood: cross-cultural codes 5. Ethnology 15(1):83106.

Baumeister, R. F., and K. D. Vohs. 2004. Sexual economics: sex as female resource for social exchange in heterosexual interactions. Personality and Social Psychology Review 8(4):339-363.

Benedict, Ruth. 1934. A defense of ethical relativism. Iournal of General Psychology 10:59-82.

Bingham, Paul M. 1999. Human uniqueness: a general theory. Quarterly Review of Biology 74(2):133-169. [HG]

Binmore, K. 1994a. Just playing, vol. 2 of Game theory and the social contract. Cambridge, MA: MIT Press.

. 1994b. Playing fair? vol. 1 of Game theory and the social contract. Cambridge, MA: MIT Press.

Bissonnette, Annie, Susan Perry, Louise Barrett, John C. Mitani, Mark Flinn, Sergey Gavrilets, and Frans B. M. de Waal. 2015. Coalitions in theory and reality: a review of pertinent variables and processes. Behaviour 152(1):156.

Bloom, P. 2004. Descartes' baby: how the science of child development explains what makes us human. New York: Basic. [PB]

. 2013. Just babies: the origins of good and evil. New York: Broadway. [PB]

Boehm, Christopher. 1999. Hierarchy in the forest: the evolution of egalitarian behavior. Cambridge, MA: Harvard University Press. [HG]

2008. Purposive social selection and the evolution of human altruism. Cross-Cultural Research 42:319-352.

Boone, J. 1992. Competition, cooperation and the development of social hierarchies. In Ecology, evolution and social behavior. E. A. Smith and B. Winterhalder, eds. Pp. 301-337. New York: de Gruyter.

Boos, M., M. Kolbe, P. M. Kappeler, and T. Ellwart, eds. 2011. Coordination in human and primate groups. London: Springer.

Bowles, Samuel, and Herbert Gintis. 2011. A cooperative species: human reciprocity and its evolution. Princeton, NJ: Princeton University Press. [HG]

Boyd, R., P. J. Richerson, and J. Henrich. 2011. The cultural niche: why social learning is essential for human adaptation. Proceedings of the National Academy of Sciences 108:10918-10925.

Brams, Steven J., and Alan D. Taylor. 1996. Fair division: from cake-cutting to dispute resolution. Cambridge: Cambridge University Press.
Brandt, Vincent S. R. 1971. A Korean village between farm and sea. Cambridge, MA: Harvard University Press.

Brosnan, Sarah F. 2013. Justice- and fairness-related behaviors in nonhuman primates. Proceedings of the National Academy of Sciences 110(suppl. 2): 10416-10423.

Brown, Christian, and E. Anthon Eff. 2010. The state and the supernatural: support for prosocial behavior. Structure and Dynamics 4(1). https://escholarship .org/uc/item/5rh6z6z6.

Brown, D. 1991. Human universals. New York: McGraw-Hill.

Bruns, Bryan. 2014. Names for games: a binomial nomenclature for $2 \times 2$ ordinal games. Presented at the International Conference on Game Theory, Stony Brook, NY, July 7-11.

Byrne, Barbara M., and Fons J. R. van de Vijver. 2014. Factorial structure of the family values scale from a multilevel-multicultural perspective. International Journal of Testing 14(2):168-192.

Carter, Gerald G. 2014. The reciprocity controversy. Animal Behavior and Cognition 1(3):368-386.

Caughey, John L. 1977. Faíaínakkar cultural values in a Micronesian society. Philadelphia: Department of Anthropology, University of Pennsylvania.

Cohen, Jacob. 1960. A coefficient of agreement for nominal scales. Educational and Psychological Measurement 20(1):37-46.

. 1968. Weighted kappa: nominal scale agreement provision for scaled disagreement or partial credit. Psychological Bulletin 70(4):213-220.

Cook, J. W. 2003. Morality and cultural differences. Oxford: Oxford University Press.

Cosmides, L., and J. Tooby. 2005. Neurocognitive adaptations designed for social exchange. In The handbook of evolutionary psychology. D. M. Buss, ed. Pp. 584-627. New York: Wiley.

Cross, Susan E., Ayse K. Uskul, Berna Gerçek-Swing, Zeynep Sunbay, Cansu Alözkan, Ceren Günsoy, Bilge Ataca, and Zahide Karakitapoğlu-Aygün. 2014. Cultural prototypes and dimensions of honor. Personality and Social Psychology Bulletin 40(2):232-249.

Curry, Oliver Scott. 2005. Morality as natural history: an adaptationist account of ethics. PhD dissertation, London School of Economics.

. 2007. The conflict-resolution theory of virtue. In Moral psychology, vol. 1. W. P. Sinnott-Armstrong, ed. Pp. 251-261. Cambridge, MA: MIT Press.

. 2016. Morality as cooperation: a problem-centred approach. In The evolution of morality. T. K. Shackelford and R. D. Hansen, eds. Pp. 27-51. New York: Springer.

Curry, Oliver Scott, Matthew Jones Chesters, and Caspar J. Van Lissa. 2019. Mapping morality with a compass: testing the theory of "morality-ascooperation" with a new questionnaire. Journal of Research in Personality 78:106-124. https://doi.org/10.1016/j.jrp.2018.10.008.

Davey, Liane M., D. Ramona Bobocel, Leanne S. Son Hing, and Mark P. Zanna. 1999. Preference for the Merit Principle Scale: an individual difference measure of distributive justice preferences. Social Justice Research 12(3):223-240.

Dawkins, R. 1979. Twelve misunderstandings of kin selection. Zeitschrift für Tierpsychologie 51(2):184-200.

. 1998. Unweaving the rainbow: science, delusion and the appetite for wonder. London: Penguin.

2006 (1976). The selfish gene. 3rd ed. Oxford: Oxford University Press. DeScioli, Peter, and Rachel Karpoff. 2015. People's judgments about classic property law cases. Human Nature 26(2):184-209.

DeScioli, Peter, and Robert Kurzban. 2009. Mysteries of morality. Cognition 112(2):281-299. doi:10.1016/j.cognition.2009.05.008. [KMS/RK]

DeScioli, Peter, M. Massenkoff, A. Shaw, M. B. Petersen, and R. Kurzban. 2014. Equity or equality? moral judgments follow the money. Proceedings of the Royal Society B 281:20142112. [KMS/RK]

Dugatkin, Lee Alan. 1997. Cooperation among animals: an evolutionary perspective. Oxford Series in Ecology and Evolution. New York: Oxford University Press.

Edel, Abraham. 1962. Anthropology and ethics in common focus. Journal of the Roval Anthropological Institute of Great Britain and Ireland 92(1):55-72.

Eff, E. Anthon, and Malcolm M. Dow. 2009. How to deal with missing data and Galton's problem in cross-cultural survey research: a primer for R. Structure and Dynamics 3(3). https://escholarship.org/uc/item/7cmlf10b.

Eisenberger, Robert, Patrick Lynch, Justin Aselage, and Stephanie Rohdieck. 2004. Who takes the most revenge? individual differences in negative reciprocity norm endorsement. Personality and Social Psychology Bulletin 30(6):787-799.

Ember, C. R., and M. Ember. 2009. Cross-cultural research methods. 2nd ed. Lanham, MD: Altamira. 
Ember, Melvin, and Keith F. Otterbein. 1991. Sampling in cross-cultural research. Behavior Science Research 25(1-4):217-233.

Ericksen, Karen Paige, and Heather Horton. 1992. "Blood feuds": cross-cultural variations in kin group vengeance. Cross-Cultural Research 26(1-4):5785.

Fiddick, Laurence, Denise Dellarosa Cummins, Maria Janicki, Sean Lee, and Nicole Erlich. 2013. A cross-cultural study of noblesse oblige in economic decision-making. Human Nature 24(3):318-335.

Foot, P. 1967. The problem of abortion and the doctrine of double effect. Oxford Review 5:5-15. [KMS/RK]

Fox, Michael W. 1999. India's sacred cow: her plight and future. Animal Issues $3(2): 1-35$.

- 2003. India's sacred cow: her plight and future. In The animal ethics reader. S. J. Armstrong and R. G. Botzler, eds. Pp. 238-241. New York: Routledge. [KMS/RK]

Fried, Jacob. 1951. Ideal norms and social control in Tarahumara society. New Haven, CT: Yale University.

Friedman, Ori, and Karen R. Neary. 2008. Determining who owns what: do children infer ownership from first possession? Cognition 107(3):829849.

Gardner, A., and S. A. West. 2014. Inclusive fitness: 50 years on. Philosophical Transactions of the Royal Society B: Biological Sciences 369(1642):20130356. Gelfand, Michele J., Jana L. Raver, Lisa Nishii, Lisa M. Leslie, Janetta Lun Beng Chong Lim, Lili Duan, et al. 2011. Differences between tight and loose cultures: a 33-nation study. Science 332(6033):1100-1104.

Georgas, James, John W. Berry, Fons J. R. van de Vijver, Cigdem Kagitçibasi, and Ype H. Poortinga, eds. 2006. Families across cultures. Cambridge: Cambridge University Press.

Gintis, Herbert. 2007. The evolution of private property. Journal of Economic Behavior and Organization 64(1):1-16. .2016. Individuality and entanglement: the moral and material bases of human social life. Princeton, NJ: Princeton University Press. [HG]

Gintis, Herbert, Eric A. Smith, and Samuel Bowles. 2001. Costly signaling and cooperation. Journal of Theoretical Biology 213:103-119.

Gintis, Herbert, Carel P. van Schaik, and Christopher Boehm. 2015. Zoon politikon: the evolutionary origins of human political systems. Current Anthropology 56(3):327-353. [HG]

Graham, J., B. A. Nosek, J. Haidt, R. Iyer, S. Koleva, and P. H. Ditto. 2011 Mapping the moral domain. Journal of Personality and Social Psychology 101(2):366-385

Gray, K., C. Schein, and A. F. Ward. 2014. The myth of harmless wrongs in moral cognition: automatic dyadic completion from sin to suffering. Journal of Experimental Psychology: General 143(4):1600-1615. [PB]

Greene, Joshua D. 2015. The rise of moral cognition. Cognition 135:39-42.

Haidt, J. 2007. The new synthesis in moral psychology. Science 316:998-1002.

2012. The righteous mind: why good people are divided by politics and religion. New York: Vintage. [PB]

Haidt, J., and J. Graham. 2007. When morality opposes justice: conservatives have moral intuitions that liberals may not recognize. Social Justice Research 20(1):98-116.

Haidt, J., and C. Joseph. 2004. Intuitive ethics: how innately prepared intuitions generate culturally variable virtues. Daedalus 133(4):55-66.

- 2011. How moral foundations theory succeeded in building on sand: a response to Suhler and Churchland. Journal of Cognitive Neuroscience 23(9):2117-2122.

Haidt, J., and S. Kesebir. 2010. Morality. In Handbook of social psychology. S Fiske, G. Gilbert, and G. Lindzey, eds. Pp. 797-832. Hoboken, NJ: Wiley.

Hamilton, W. D. 1963. The evolution of altruistic behavior. American Naturalist 97:354-356.

1964. The genetical evolution of social behaviour. Lournal of Theoretical Biology 7:1-16, 17-52.

Hammerstein, P., ed. 2003. Genetic and cultural evolution of cooperation. Cambridge, MA: MIT Press.

Harcourt, A., and F. B. M. de Waal, eds. 1992. Coalitions and alliances in humans and other animals. Oxford: Oxford University Press.

Hardy, C. W., and M. Briffa, eds. 2013. Animal contests. Cambridge: Cambridge University Press.

Hare, Darragh, Hudson Kern Reeve, and Bernd Blossey. 2016. Evolutionary routes to stable ownership. Iournal of Evolutionary Biology. 29(6):1178-1188.

Henrich, J., R. Boyd, S. Bowles, C. Camerer, E. Fehr, H. Gintis, R. McElreath, et al. 2005. "Economic man" in cross-cultural perspective: behavioral experiments in 15 small-scale societies. Behavioral and Brain Sciences 28(6):795855.
Henrich, Joseph, Robert Boyd, and Peter J. Richerson. 2012. The puzzle of monogamous marriage. Philosophical Transactions of the Royal Society B: Biological Sciences 367(1589):657-669.

Henrich, J., S. J. Heine, and A. Norenzayan. 2010. Beyond WEIRD: towards a broad-based behavioral science. Behavioral and Brain Sciences 33(23):111-135.

Herskovits, M. J. 1952. Economic anthropology: a study in comparative economics. New York: Knopf.

HRAF. 1967. The HRAF quality control sample universe. Cross-Cultural Research 2(2):81-88.

Hrdy, Sarah Blaffer. 2000. Mother Nature: maternal instincts and how they shape the human species. New York: Ballantine. [HG]

Hume, David. 1748. Philosophical essays concerning human understanding. London: A. Millar.

. 1751. An enquiry concerning the principles of morals. London: A. Millar Huntingdon, F. A., and A. K. Turner. 1987. Animal conflict. London: Chapman \& Hall.

Inglehart, R., and W. E. Baker. 2000. Modernization, cultural change, and the persistence of traditional values. American Sociological Review 65(1):1951.

Jaeggi, Adrian V., and Michael Gurven. 2013. Reciprocity explains food sharing in humans and other primates independent of kin selection and tolerated scrounging: a phylogenetic meta-analysis. Proceedings of the Royal Society of London B: Biological Sciences 280(1768). doi:10.1098/rspb.2013.1615.

Jeon, J., Chorong Kim, and J. C. Choe. 2016. Disgust and status hierarchy. Paper presented at 28th Annual Human Behavior and Evolution Society Conference, Vancouver, July 1.

Johnson, Dominic D. P., and Monica Duffy Toft. 2014. Grounds for war: the evolution of territorial conflict. International Security 38(3):7-38.

Jones, Marshall B., and Donald R. Jones. 2000. The contagious nature of antisocial behavior. Criminology 38(1):25-46.

Kahneman, D., and A. Tversky. 1979. Prospect theory: an analysis of decision under risk. Econometrica 47(2):263-291.

Krippendorff, Klaus. 2012. Content analysis: an introduction to its methodology. Thousand Oaks, CA: Sage.

Kruger, Daniel J., Maryanne Fisher, and Ian Jobling. 2003. Proper and dark heroes as DADS and CADS. Human Nature 14(3):305-317.

Kurland, J., and S. Gaulin. 2005. Cooperation and conflict among kin. In The handbook of evolutionary psychology. D. M. Buss, ed. Pp. 447-482. Hoboken, NJ: Wiley.

Kurzban, Robert, Peter DeScioli, and Daniel Fein. 2012. Hamilton vs. Kant: pitting adaptations for altruism against adaptations for moral judgment. Evolution and Human Behavior 33:323-333. [KMS/RK]

Kurzban, Robert, A. Dukes, and J. Weeden. 2010. Sex, drugs and moral goals: reproductive strategies and views about recreational drugs. Proceedings of the Royal Society B: Biological Sciences 277:3501-3508.

Lagacé, Robert O. 1979. The HRAF probability sample: retrospect and prospect. Cross-Cultural Research 14(3):211-229.

Laidlaw, James. 2002. For an anthropology of ethics and freedom. Lournal of the Roval Anthropological Institute 8(2):311-332.

2013. The subject of virtue. Cambridge: Cambridge University Press.

Landis, J. Richard, and Gary G. Koch. 1977. The measurement of observer agreement for categorical data. Biometrics 33(1):159-174.

Lang, Hartmut. 1998. CONAN: an electronic code-text data-base for crosscultural studies. World Cultures 9(2):13-56.

Lehmann, L., and L. Keller. 2006. The evolution of cooperation and altruisma general framework and a classification of models. Journal of Evolutionary Biology 19(5):1365-1376.

Levine, Donald Nathan. 1965. Wax and gold: tradition and innovation in Ethiopian culture. Chicago: University of Chicago Press.

Lewis, D. K. 1969. Convention: a philosophical study. Cambridge, MA: Harvard University Press.

Lieberman, D., J. Tooby, and L. Cosmides. 2003. Does morality have a biological basis? an empirical test of the factors governing moral sentiments relating to incest. Proceedings of the Roval Society of London Series BBiological Sciences 270(1517):819-826. 731

Locke, J. 1690. An essay concerning human understanding. London: Thomas Bassett.

Mace, Ruth, Mark Pagel, John R. Bowen, Keith F. Otterbein, Mark Ridley, Thomas Schweizer, and Eckart Voland. 1994. The comparative method in anthropology [and comments and reply]. Current Anthropology 35(5):549-564. 
Machery, E., and R. Mallon. 2010. The evolution of morality. In The moral psychology handbook. J. Doris, ed. Pp. 3-46. Oxford: Oxford University Press Maine, H. J. S. 1861. Ancient law. London: Murray.

Majumdar, Dhirendra Narayan. 1978. A study of culture change in two Garo villages. Calcutta: Anthropological Survey of India, Government of India.

Maxwell, K. B. 1983. Bemba myth and ritual: the impact of literacy on an oral culture. New York: Lang.

Maynard Smith, J. 1982. Evolution and the theory of games. Cambridge: Cambridge University Press.

Maynard Smith, J., and G. R. Price. 1973. The logic of animal conflict. Nature 246:15-18.

Maynard Smith, J., and E. Szathmáry. 1995. The major transitions in evolution. Oxford: Oxford University Press.

Mazur, A. 2005. Biosociology of dominance and deference. Lanham, MD: Rowan \& Littlefield.

McElreath, R., R. Boyd, and P. J. Richerson. 2003. Shared norms and the evolution of ethnic markers. Current Anthropology 44(1):122-129.

McKay, R., and H. Whitehouse. 2014. Religion and morality. Psychological Bulletin 141(2):447-473.

Messick, D. M. 1993. Equality as a decision rule. In Psychological perspectives on justice. B. Mellers and J. Baron, eds. Pp. 11-31. Cambridge: Cambridge University Press.

Messing, Simon D., and M. Lionel Bender. 1985. Highland plateau Amhara of Ethiopia. New Haven, CT: Human Relations Area Files.

Mikhail, John. 2007. Universal moral grammar: theory, evidence and the future. Trends in Cognitive Sciences 11(4):143-152. doi:10.1016/j.tics.2006.12.007. [KMS/RK]

2011. Elements of moral cognition: Rawls' linguistic analogy and the cognitive science of moral and legal judgment. Cambridge: Cambridge University Press. [PB]

Mock, D. W. 2004. More than kin and than kind: the evolution of family conflict. Cambridge, MA: Harvard University Press. [KMS/RK]

Moll, Jorge, Frank Krueger, Roland Zahn, Matteo Pardini, Ricardo de Oliveira-Souza, and Jordan Grafman. 2006. Human fronto-mesolimbi networks guide decisions about charitable donation. Proceedings of the National Academy of Sciences 103(42):15623-15628. [DBW]

Murdock, G. P., and D. R. White. 2006. Standard cross-cultural sample: on line edition. Social Dynamics and Complexity working paper. Irvine: University of California. https://escholarship.org/uc/item/62c5c02n

Nagel, T. 1991. Mortal questions. Cambridge: Canto.

Naroll, Raoul. 1967. The proposed HRAF probability sample. Cross-Cultural Research 2(2):70-80.

Nash, J. 1950. The bargaining problem. Econometrica 18(2):155-162.

Newman, G. 1976. Comparative deviance: perception and law in six cultures. New York: Elsevier.

Nunn, C. L., and R. J. Lewis. 2001. Cooperation and collective action in animal behaviour. In Economics in nature: social dilemmas, mate choice and biological markets. Cambridge: Cambridge University Press.

Ostrom, Lin, and James Walker, eds. 2002. Trust and reciprocity: interdisciplinary lessons from experimental research. New York: Russell Sage.

Otterbein, Keith F. 1969. Basic steps in conducting a cross-cultural study. Cross-Cultural Research 4(3):221-236.

Park, N., Christopher Peterson, and Martin E. P. Seligman. 2006. Character strengths in fifty-four nations and the fifty US states. Iournal of Positive Psychology 1(3):118-129.

Penke, Lars, and Jens B. Asendorpf. 2008. Beyond global sociosexual orientations: a more differentiated look at sociosexuality and its effects on courtship and romantic relationships. Journal of Personality and Social Psychology 95(5):1113-1135.

Perugini, M., M. Gallucci, F. Presaghi, and A. P. Ercolani. 2003. The personal norm of reciprocity. European Journal of Personality 17(4):251-283.

Peterson, Christopher, and Martin E. P. Seligman. 2004. Character strength and virtues: $a$ handbook and classification. Washington, DC: American Psychological Association/Oxford University Press.

Pinker, S. 2010. The cognitive niche: coevolution of intelligence, sociality, and language. Proceedings of the National Academy of Sciences of the United States of America 107:8993-8999.

Pinsof, David, and Martie G. Haselton. 2016. The political divide over samesex marriage: mating strategies in conflict? Psychological Science 27(4):435 442. [KMS/RK]

2017. The effect of the promiscuity stereotype on opposition to gay rights. PLoS ONE 12(7):e0178534.

Popper, K. R. 1945. The open society and its enemies. London: Routledge.
Pospisil, Leopold J. 1958. Kapauku Papuans and their law. New Haven, CT: Yale University.

Preuschoft, S., and C. P. van Schaik. 2000. Dominance and communication: conflict management in various social settings. In Natural conflict resolution. F. Aureli and F. B. M. de Waal, eds. Pp. 77-105. Berkeley: University of California Press.

Price, Michael E., Nicholas Pound, and Isabel M. Scott. 2014. Female economic dependence and the morality of promiscuity. Archives of Sexual Behavior 43(7):1289-1301.

Prinz, J. 2007. Is morality innate? In Moral psychology. W. P. SinnottArmstrong, ed. Pp. 367-406. Cambridge, MA: MIT Press.

Rai, Tage Shakti, and A. P. Fiske. 2011. Moral psychology is relationship regulation: moral motives for unity, hierarchy, equality, and proportionality. Psychological Review 118(1):57-75.

Riechert, S. E. 1998. Game theory and animal contests. In Game theory and animal behavior. L. A. Dugatkin and H. K. Reeve, eds. Pp. 64-93. Oxford: Oxford University Press.

Robinson, D. R., and D. J. Goforth. 2005. The topology of $2 \times 2$ games: a new periodic table. London: Routledge.

Rose, Carol M. 1985. Possession as the origin of property. University of Chicago Law Review 52:73-88.

Ross, Marc Howard. 1983. Political decision making and conflict: additional cross-cultural codes and scales. Ethnology 22(2):169-192.

Rubin, P. H. 2000. Hierarchy. Human Nature 11(3):259-279.

Sachs, J. L., U. G. Mueller, T. P. Wilcox, and J. J. Bull. 2004. The evolution of cooperation. Quarterly Review of Biology 79(2):135-160.

Schmitt, David P., and David M. Buss. 2001. Human mate poaching: tactics and temptations for infiltrating existing mateships. Lournal of Personality and Social Psychology 80(6):894-917.

Schwartz, S. H. 1992. Universals in the content and structure of values: theory and empirical tests in 20 countries. In Advances in experimental social psychology. M. Zanna, ed. Pp. 1-66. New York: Academic.

Sell, A., J. Tooby, and L. Cosmides. 2009. Formidability and the logic of human anger. Proceedings of the National Academy of Sciences of the United States of America 106(35):15073-15078.

Shackelford, Todd K., and Ranald D. Hansen, eds. 2016. The evolution of morality: New York: Springer.

Sheskin, Mark, Coralie Chevallier, Stéphane Lambert, and Nicolas Baumard. 2014. Life-history theory explains childhood moral development. Trends in Cognitive Sciences 18(12):613-615.

Shultz, Susanne, Christopher Opie, and Quentin D. Atkinson. 2011. Stepwise evolution of stable sociality in primates. Nature 479(7372):219-222.

Sinnott-Armstrong, W., ed. 2007. Moral psychology, vol. 1-3. Cambridge, MA: MIT Press.

Skyrms, B. 1996. Evolution of the social contract. Cambridge: Cambridge University Press.

Slone, D. Jason. 2004. Theological incorrectness: why religious people believe what they shouldn't. Oxford: Oxford University Press.

Spencer, Paul. 1988. The Maasai of Matapato: a study of rituals of rebellion. Bloomington: Indiana University Press.

Sripada, C. S., and S. Stich. 2006. A framework for the psychology of norms. In The innate mind: culture and cognition, vol. 2. P. Carruthers, S. Laurence, and S. Stich, eds. Pp. 280-301. Oxford: Oxford University Press. Stanford, P. Kyle. 2018. The difference between ice cream and Nazis: moral externalization and the evolution of human cooperation. Behavioral and Brain Sciences 41:E95. doi:10.1017/S0140525X17001911.

Sterelny, K. 2010. Moral nativism: a sceptical response. Mind and Lanquage 25(3):279-297.

Sterelny, K., and Benjamin Fraser. 2016. Evolution and moral realism. British Journal for the Philosophy of Science 68(4):981-1006.

Strassmann, Joan E., and David C. Queller. 2014. Privatization and property in biology. Animal Behaviour 92:305-311.

Tomasello, Michael. 2016. A natural history of human morality. Cambridge, MA: Harvard University Press. [DBW]

Tomasello, Michael, and Amrisha Vaish. 2013. Origins of human cooperation and morality. Annual Review of Psychology 64(1):231-255.

Tooby, J., and L. Cosmides. 1992. The psychological foundations of culture. In The adapted mind: evolutionary psychology and the generation of culture. J. H. Barkow, L. Cosmides, and J. Tooby, eds. Pp. 19-136. New York: Oxford University Press.

Tooby, J., and I. DeVore. 1987. The reconstruction of hominid behavioral evolution through strategic modeling. In The evolution of human behavior: primate models. W. G. Kinzey, ed. Pp. 183-237. Albany, NY: SUNY Press. 
Trivers, R. L. 1971. The evolution of reciprocal altruism. Quarterly Review of Biology 46(1):35-57.

Turchin, Peter, Rob Brennan, Thomas Currie, Kevin Feeney, Pieter Francois, Daniel Hoyer, Joseph Manning, et al. 2015. Seshat: the global history databank. Cliodynamics 6(1). doi:10.21237/C7clio6127917.

Turchin, Peter, H. Whitehouse, P. Franc, ois, E. Slingerland, and M. Collard. 2012. A historical database of sociocultural evolution. Cliodynamics 3:271-293.

Von Neumann, J., and O. Morgenstern. 1944. The theory of games and economic behavior. Princeton, NJ: Princeton University Press.

Weeden, Jason, and Robert Kurzban. 2013. What predicts religiosity? a multinational analysis of reproductive and cooperative morals. Evolution and Human Behavior 34(6):440-445.
Whitehouse, H. 2016. Developing the field site concept for the study of cultural evolution: an anthropologist's view. Evolution Institute, October 19. https://evolution-institute.org/commentary/developing-the-field-site-concept -for-the-study-of-cultural-evolution-the-promise-and-the-perils/.

Whyte, Martin K. 2005. The status of women in preindustrial societies. 2nd ed. Princeton, NJ: Princeton University Press.

Wilson, M., and M. Daly. 1992. The man who mistook his wife for a chattel. In The adapted mind: evolutionary psychology and the generation of culture. J. H. Barkow, L. Cosmides, and J. Tooby, eds. Pp. 289-326. New York: Oxford University Press.

Wong, David. 2006. Natural moralities: a defense of pluralistic relativism. New York: Oxford University Press.

This content downloaded from 163.001.203.194 on February 10, 2020 04:04:08 AM 